\title{
Behaviour of structural stainless steel cross-sections under combined \\ loading - Part II: Numerical modeling and design approach
}

\author{
Ou Zhao ${ }^{\text {a }}$, Barbara Rossi ${ }^{\mathrm{b}}$, Leroy Gardner ${ }^{\mathrm{a}}$, Ben Young ${ }^{\mathrm{c}}$ \\ ${ }^{\text {a }}$ Imperial College London, Dept. of Civil and Environmental Engineering, London, UK \\ ${ }^{\mathrm{b}}$ KU Leuven, Dept. of Civil Engineering, Belgium \\ ${ }^{\mathrm{c}}$ The University of Hong Kong, Dept. of Civil Engineering, Hong Kong, China
}

\begin{abstract}
In parallel with the experimental study described in the companion paper [1], a numerical modelling programme has been carried out to investigate further the structural behaviour of stainless steel cross-sections under combined loading. The numerical models, which were developed using the finite element (FE) package ABAQUS, were initially validated against the experiments, showing the capability of the FE models to replicate the key test results, full experimental load-deformation histories and observed local buckling failure modes. Upon validation of the FE models, parametric studies were conducted to generate additional structural performance data over a wide range of cross-section slenderness and combinations of loading. The experimental and numerical results were then compared with the design capacity predictions from the current European Standard EN 1993-1-4 (2006) [2] and American Specification SEI/ASCE-8 (2002) [3] for stainless steel. The comparisons revealed that the current design standards can significantly under-estimate the resistance of stainless steel cross-sections subjected to combined loading; this under-prediction of capacity can be attributed primarily to the lack of consideration of strain hardening of the material under load. The Continuous Strength Method (CSM) is a deformation-based design approach that
\end{abstract}


accounts for strain hardening and has been shown to provide accurate predictions of crosssectional resistance under compression and bending, acting in isolation. Proposals are made in the present paper to extend the scope of the CSM to the case of combined loading. Comparisons between the CSM design proposals and the test and FE results indicated a high level of accuracy and consistency in the predictions. The reliability of the proposals were confirmed by means of statistical analyses according to EN 1990-Annex D [4].

\section{Introduction}

Recent years have witnessed increasing interest in the use of cold-formed stainless steel tubular sections in a variety of engineering applications owing to their durability and appearance, combined with excellent mechanical properties. Although a number of established structural design codes for stainless steel exist, previous studies [5-12] have highlighted limitations and undue conservatism in some of their provisions. This has prompted research aimed at broadening the scope and enhancing the efficiency of these codes. A brief review of the key studies relevant to the context of the present paper follows. At cross-sectional level, existing design codes [2-3] generally utilise traditional methods for the treatment of structural stainless steel cross-sections, namely section classification and the effective width concept. More recent design codes and guidance [13-14] have included more advanced design methods, including the Continuous Strength Method (CSM) for the design of stocky stainless steel cross-sections [13] and the Direct Strength Method (DSM) for slender stainless steel cross-sections and members [14]. The underpinning research for the CSM was reported in [15-17], while the DSM developments were described by [18-19]. At member level, the European provisions for stainless steel member design mirror those for carbon steel but with different imperfection factors to reflect the particular characteristics of 
stainless steel. The American Specification SEI/ASCE-8 (2002) [3] utilises the tangent stiffness in the design of stainless steel members, which yields accurate capacity predictions, but needs iterative calculations. Revised buckling curves, covering both flexural and lateral torsional instabilities, were proposed in [20-21]. With regards to beam-column design, both EN 1993-1-4 (2006) [2] and SEI/ASCE-8 (2002) [3] employ interaction formulae, with the end points being the member capacities under the individual loading conditions. Revised interaction formulae have been proposed by Greiner and Kettler [22], Lopes et al. [23] and Huang and Young [24].

The focus of the present paper is the assessment of existing codified approaches and the development of new efficient methods for the design of stainless steel cross-sections under combined loading, based on the experimental results from the companion paper [1] and numerical simulations conducted herein. The numerical modelling programme was carried out initially to replicate the test results reported in the companion paper [1]. Upon validation of the FE models, parametric studies were performed to expand the available results over a wider range of cross-section slenderness. The experimental and numerical results were then compared against the strength predictions determined according to EN 1993-1-4 (2006) [2] and SEI/ASCE-8 (2002) [3], enabling the accuracy of each codified method to be assessed. Finally, the accuracy of the deformation-based CSM was assessed for combined loading, with both a simplified and more complex treatment examined. 


\section{Numerical modelling}

\subsection{Introduction}

In conjunction with the experimental study described in the companion paper [1], a numerical modelling programme was performed by adopting the general-purpose finite element analysis package ABAQUS [25]. The aims of the investigations were initially to replicate the full experimental load-deformation histories and to assess the sensitivity of the FE models to various input parameters, and subsequently to conduct parametric studies to generate further structural performance data to supplement the experimental results for further analysis.

\subsection{Basic modelling assumptions}

The four-noded doubly curved shell element with reduced integration and finite membrane strain, S4R [25], was selected as the element type throughout the present numerical investigation, which has been shown to perform well in similar studies $[8-9,26]$ concerning the modelling of thin-walled structures. An element size equal to the cross-section thickness was assigned to the flat parts of the modelled cross-sections, and a finer mesh of 5 elements was used in the corner regions to ensure the curved geometry could be accurately represented. The two-stage Ramberg-Osgood ( $\mathrm{R}-\mathrm{O})$ material model [27], which is an extension of the basic Ramberg-Osgood formulations [28-29] and followed developments by Mirambell and Real [30] and Rasmussen [31], was employed to represent the experimental stress-strain curves. Since ABAQUS requires the material properties to be defined in the format of true stress and log plastic strain, the measured engineering stress-strain curves were converted 
into the true stress-log plastic strain curves, by means of Eq. (1) and Eq. (2), before inputting into ABAQUS,

$\sigma_{\text {true }}=\sigma_{\text {nom }}\left(1+\varepsilon_{\text {nom }}\right)$

$\varepsilon_{l n}^{p l}=\ln \left(1+\varepsilon_{\text {nom }}\right)-\frac{\sigma_{\text {true }}}{E}$

in which $\sigma_{\text {true }}$ is the true tress, $\varepsilon_{l n}^{p l}$ is the logarithmic plastic strain, $E$ is the Young's modulus, and $\sigma_{\text {nom }}$ and $\varepsilon_{\text {nom }}$ are the engineering stress and strain, respectively.

The examined cross-sections were produced by cold-rolling. This process induces plastic deformations, resulting in strength enhancements, which are most notable in the corner regions. It has been both experimentally [32-33] and numerically [26, 34] verified that the high corner strength enhancements are not restricted only to the curved portions of the section, but also extend into the adjacent flat parts by a distance approximately equal to two times the cross-section thickness. This finding has been adopted in the present numerical study by assigning corner material properties to both of the aforementioned regions. Note that strength enhancements also arise in the flat regions of cold-rolled hollow sections, but these are already reflected in the stress-strain properties of the tested flat coupons.

Residual stresses are also introduced into the specimens during the production process, with a combination of through-thickness bending residual stresses due to cold-forming and membrane residual stresses from welding. For cold-rolled and seam-welded stainless steel tubular sections, Cruise and Gardner [35], Huang and Young [36] and Jandera et al. [37] carried out careful residual stress measurements and concluded that the magnitude of the membrane residual stresses was small compared to that of the bending residual stresses. In addition, as highlighted in [35, 37-38], the effect of the through-thickness bending residual 
stresses is inherently incorporated into the measured material properties, since the coupons straighten during tensile testing. Thus, explicit inclusion of residual stresses in the numerical models was deemed unnecessary.

FE models were created to simulate the tested concentrically and eccentrically loaded stub columns, and beams. The following end section boundary conditions were employed in the respective models: For the concentric stub columns, which had fixed ends, the nodes of each end cross-section were coupled to a concentric reference point, where all degrees of freedom were restrained at one end and all degrees of freedom except for longitudinal translation were fixed at the loaded end. For each combined loading stub column FE model, the end section was coupled with an eccentric reference point, allowing rotation about the axis of buckling at one end and the same rotation plus longitudinal translation at the loaded end, in order to simulate pin-ended boundary conditions. In addition, the eccentric reference point was offset longitudinally from the end section by a distance equal to the thickness of the welded end plate $(25 \mathrm{~mm})$ in order to accurately model the effective member length. Similar end section boundary conditions as those for the combined loading stub column FE models were applied to the four-point bending FE models, with the only difference being that the reference point was located at the mid-point of the bottom flange; these boundary conditions replicated the simply-supported conditions employed in the beam tests.

Initial local geometric imperfections exist in all thin-walled structural members and can influence the development of local buckling, the local level at which plasticity initiates, the ultimate load-carrying capacity and the post-ultimate response. Hence, it is necessary to include suitable geometric imperfections into the FE models in order to replicate accurately the observed experimental response. Previous numerical studies [26, 34, 39-40] have adopted 
an imperfection pattern along the member length in the form of the lowest buckling mode shape, which was determined by performing a prior elastic eigenvalue buckling analysis; this approach was also employed herein. Upon the incorporation of the initial geometric imperfection into the FE model, geometrically and materially nonlinear analyses were carried, using the modified Riks method [25] to trace the full load-deformation response of the specimens, including the post-ultimate path. The sensitivity of the models to imperfections was examined by considering three different imperfection amplitudes. The three considered values were the maximum measured imperfection amplitude $\omega_{0}$, as reported in the companion paper [1], 1/100 of the cross-section thickness and the imperfection amplitude derived from the modified Dawson and Walker (D\&W) predictive model [26, 41], as given by Eq. (3), where $\sigma_{c r, \min }$ is the minimum elastic buckling stress of all the plate elements making up the cross-section and $\sigma_{0.2}$ is the $0.2 \%$ proof stress.

$$
\omega_{0}=0.023\left(\frac{\sigma_{0.2}}{\sigma_{c r, \min }}\right) t
$$

\subsection{Validation of numerical models}

The accuracy of the FE models was assessed by comparing the key results, full loaddeformation histories and local buckling failure modes obtained from tests with those derived from the numerical simulations. The key results (i.e. ultimate load and deformation at ultimate load) from the numerical simulations, for the various considered imperfection levels, have been normalised by the corresponding experimental results from the stub column tests, four-point bending tests, uniaxial bending plus compression tests and biaxial bending plus compression tests, and tabulated in Tables 1-4 respectively. It may be observed that the ultimate loads $N_{u}$ and moments $M_{u}$ derived from the numerical models generally showed 
relatively insensitivity to the changes in the imperfection amplitudes whereas the corresponding deformation parameters, including the end-shortening $\delta_{u}$ from the stub column FE models, the curvature $\kappa_{u}$ from the four-point bending FE models and the end rotation $\phi_{u}$ from the combined loading stub column FE models, were substantially more sensitive. The best agreement between the test and FE results was generally achieved when the measured imperfection amplitudes were employed in the models, but using the imperfection amplitudes predicted by the modified Dawson and Walker expression also yielded accurate and consistent results.

Typical numerical load-deformation curves using the measured imperfection amplitudes are compared with the corresponding experimental curves from the stub column tests, four-point bending tests, uniaxial bending plus compression tests and biaxial bending plus compression tests in Figs 1-4, respectively, where the solid lines represent the test curves while the dashed lines are the numerical counterparts. The comparisons show that the key characteristics, including the initial stiffness, the general shape of the experimental curve and the postultimate response, are all accurately captured. The local buckling failure modes from numerical studies are also in good agreement with those from experiments, as displayed in Figs 5-8. Overall, it may be concluded that the finite element models are capable of accurately capturing the key test results, replicating the full experimental load-deformation histories and predicting the observed failure modes.

\subsection{Parametric studies}

Upon validation of the numerical models, a series of parametric studies was carried out to generate further structural performance data over a wider range of cross-section slenderness. 
The parametric studies focus primarily on austenitic stainless steel, although comparative studies are also performed on the lean duplex grade. Further to the basic modelling assumptions described previously, some supplementary details are provided herein. For each stainless steel grade, the average material properties from the tensile coupon tests carried out in this study were adopted in the FE parametric studies. The initial local imperfection amplitudes were determined by means of the modified Dawson and Walker model. For all the modelled cross-sections, the outer width was set equal to $100 \mathrm{~mm}$ while the outer depth was equal to either $100 \mathrm{~mm}$ or $150 \mathrm{~mm}$. The internal corner radii were equal to the cross-section thickness and the length of each model was set to be equal to four times its mean outer dimension. The cross-section thickness was varied from $3.7 \mathrm{~mm}$ to $12 \mathrm{~mm}$ and the initial loading eccentricities ranged between $5 \mathrm{~mm}$ and $210 \mathrm{~mm}$, leading to a wide range of crosssection slenderness and loading conditions being considered. The numerical results from the parametric studies, together with the experimental data, are used in the following section for the assessment and development of design expressions for stainless steel cross-sections under combined loading.

\section{Assessment of codified design rules and development of new design methods}

\subsection{General}

In this section, the codified design provisions for stainless steel cross-sections under combined loading, as given in EN 1993-1-4 (2006) [2] and SEI/ASCE-8 (2002) [3], are firstly examined. Then, extension of the deformation-based Continuous Strength Method (CSM) to the case of combined loading is described. The accuracy of each method is evaluated, as reported in Tables 5-6 and Tables 7-8 for austenitic and lean duplex stainless 
steels, respectively, by means of the ratio of the test (or FE) to predicted capacities $R_{u} / R_{u, p r e d}$, in which $R_{u}$ is the distance from the origin of the $\mathrm{N}-\mathrm{M}$ interaction curve to the test (or FE) data point (see Fig. 9), while $R_{u, p r e d}$ is the distance from the origin to the intersection with the design interaction curve, assuming proportional loading. A value of $R_{u} / R_{u, \text { pred }}$ greater than unity indicates that the test (or FE) data point lies outside the interaction curve and is safely predicted. Note that all comparisons have been made based on the measured material and geometric properties and that all partial factors have been set equal to unity. According to EN 1993-1-4 (2006) [2], all the modelled cross-sections are classified as at least class 3, while all the tested sections are class 1 except for the SHS $120 \times 120 \times 5$ which is class 3 .

\subsection{European code EN 1993-1-4 (EC3)}

The European structural design code for stainless steel, EN 1993-1-4 (2006) [2] does not contain specific provisions for cross-section resistance under combined loading, but simply adopts the relevant carbon steel design expressions given in EN 1993-1-1 (2002) [42]. For class 3 sections, linear elastic interaction formulae are employed, limiting stresses at any point in the cross-section to the $0.2 \%$ proof stress $\sigma_{0.2}$, as shown in Eq. (4), where the following symbols are used: $M_{e l, y}$ and $M_{e l, z}$ are the elastic moment capacities about the major and minor axes, respectively equal to the corresponding elastic section moduli $W_{e l, y}$ and $W_{e l, \mathrm{z}}$ multiplied by $\sigma_{0.2}, N_{E d}$ is the applied design axial load, $M_{E d, y}=N_{E d}\left(e_{0 y}+e_{y}^{\prime}\right)$ and $M_{E d, \mathrm{z}}=N_{E d}\left(e_{0 z}+e_{z}^{\prime}\right)$ are the applied design bending moments about the two principal axes, in which $e_{0 y}$ and $e_{0 z}$ are the initial loading eccentricities while $e_{y}^{\prime}$ and $e_{z}^{\prime}$ are the generated 
lateral deflections at failure. For class 4 cross-sections, the effective section properties are employed in place of the gross section properties in Eq. (4).

$$
\frac{N_{E d}}{A \sigma_{0.2}}+\frac{M_{E d, y}}{M_{e l, y}}+\frac{M_{E d, z}}{M_{e l, z}} \leq 1
$$

With respect to class 1 and 2 cross-sections, stress redistribution is allowed for by assuming full plasticity throughout the cross-section at failure, leading to the bi-linear interaction formulae given by Eqs (5) and (6) for RHS under major axis bending plus compression and minor axis bending plus compression, respectively, and the nonlinear interaction formula given by Eq. (7) for RHS under biaxial bending plus compression, where $M_{p l, y}$ and $M_{p l, z}$ are the major and minor axis plastic moment capacities, respectively equal to the corresponding plastic section moduli $W_{p l, y}$ and $W_{p l, z}$ multiplied by $\sigma_{0.2}, M_{R, y}$ and $M_{R, z}$ are the reduced plastic moment capacities about the major and minor axes due to the presence of the axial force $N_{E d}, n$ is equal to $N_{E d} / A \sigma_{0.2}, a_{w}$ and $a_{f}$ are the ratios of the web area $A_{w}$ and flange area $A_{f}$ to the gross area $A$, respectively, and $\alpha$ and $\beta$ are the interaction coefficients for biaxial bending defined as $1.66 /\left(1-1.13 n^{2}\right)$.

$$
\begin{aligned}
& M_{E d, y} \leq M_{R, y}=M_{p l, y} \frac{(1-n)}{\left(1-0.5 a_{w}\right)} \leq M_{p l, y} \\
& M_{E d, z} \leq M_{R, z}=M_{p l, z} \frac{(1-n)}{\left(1-0.5 a_{f}\right)} \leq M_{p l, z} \\
& {\left[\frac{M_{E d, y}}{M_{R, y}}\right]^{\alpha}+\left[\frac{M_{E d, z}}{M_{R, z}}\right]^{\beta} \leq 1}
\end{aligned}
$$

Figs 10-11 depict the normalised uniaxial bending plus compression test and FE results, arranged by cross-section class, together with the average codified interaction curves, for austenitic and lean duplex stainless steels, respectively. The comparisons reveal a high degree of scatter and increasing conservatism as the cross-sections become more stocky (i.e. moving 
from class 3 to class 1). For the austenitic stainless steel sections, Tables 5-6 show that the mean ratios of test (or $\mathrm{FE}$ ) to EC3 capacities $R_{u} / R_{u, E C 3}$ are respectively 1.31 , with a Coefficient of Variation (COV) equal to $10.5 \%$ for uniaxial bending plus compression cases, and 1.24 with a COV of $13.9 \%$ for biaxial bending plus compression cases. The rather conservative and scattered nature of the EC3 predictions stems principally from the neglect of strain hardening, which limits the end points of the interaction curves to the elastic or plastic moment capacities $\left(M_{e l}\right.$ and $M_{p l}$ ) and yield load $A \sigma_{0.2}$. For the lean duplex stainless steel, which exhibits a lesser degree of strain hardening, conservatism and scatter are again present in the EC3 predictions, but to a less pronounced extent than for the austenitic grade, as shown in Tables $7-8$.

\subsection{American Specification SEI/ASCE-8}

The American Specification SEI/ASCE-8 (2002) [3] employs the same set of interaction equations for both short (cross-section) and long (global) beam-column design. The interaction expression is given by Eq. (8), in which $N_{n}, M_{n y}$ and $M_{n z}$ are the codified crosssectional compression and bending resistances, $C_{m y}$ and $C_{m z}$ are the equivalent uniform moment factors which are equal to unity for a beam-column with constant first order bending moment along the member length, and $\alpha_{n y}$ and $\alpha_{n z}$ are the magnification factors equal to $\left(1-N_{E d} / N_{E}\right)$, which approximate to unity for short (cross-section) beam-column behaviour since $N_{E d}$ is much smaller than the Euler buckling load $N_{E}=\pi^{2} E I / L^{2}$. Thus, Eq. (8) reduces to the linear interaction given by Eq. (9). For the calculation of cross-sectional bending resistances $M_{n y}$ and $M_{n z}$, Procedure II set out in clause 3.3.1.1 of SEI/ASCE-8 (2002) [3] was employed, which accounts for partial plasticity by adopting a compression 
strain factor $C_{y}$ to determine the maximum compressive strain $C_{y} \sigma_{0.2} / E$ and then assumes an elastic-plastic stress distribution throughout the cross-section. The cross-sectional bending resistance calculated in accordance with SEI/ASCE-8 (2002) [3] therefore always lies between the elastic $M_{e l}$ and plastic $M_{p l}$ moment capacity.

$$
\begin{aligned}
& \frac{N_{E d}}{N_{n}}+\frac{C_{m y} M_{E d, y}}{M_{n y} \alpha_{n y}}+\frac{C_{m z} M_{E d, z}}{M_{n z} \alpha_{n z}} \leq 1 \\
& \frac{N_{E d}}{N_{n}}+\frac{M_{E d, y}}{M_{n y}}+\frac{M_{E d, z}}{M_{n z}} \leq 1
\end{aligned}
$$

For class 1 and 2 sections, the SEI/ASCE-8 Specification yields significantly less accurate strength predictions than EN 1993-1-4, due to the use of a linear interaction expression, rather than convex nonlinear interaction curves as employed in the Eurocode, and the adoption of lower bending resistances as the end points of the interaction curves. For class 3 crosssections, both codes use a linear interaction formula, but SEI/ASCE-8 (2002) [3] is marginally more accurate than the Eurocode due to the allowance for partial spread of plasticity. As shown in Tables 5-8, the SEI/ASCE-8 design provisions result in mean test (or FE) to predicted resistance ratios $R_{u} / R_{u, A S C E}$ for the austenitic stainless steel sections of 1.42 and 1.76 for stub columns under uniaxial eccentric compression and biaxial eccentric compression, respectively, while for the lean duplex stainless steel, the corresponding mean values are 1.34 and 1.60, all of which are higher than the EN 1993-1-4 values, indicating greater conservatism.

\subsection{Continuous Strength Method (CSM)}

The Continuous Strength Method (CSM) is a deformation-based design approach that enables a rational exploitation of strain hardening. The method has been shown to give a high level of 
accuracy and consistency in predicting the resistance of stainless steel cross-sections under isolated loading [15-17], and proposals to extend the method to cover the case of combined loading have recently been made [43]. The main characteristics of the CSM lie in the employment of a 'base curve' to determine the maximum attainable strain $\varepsilon_{c s m}$ for a given cross-section, and the adoption of a strain hardening material model, which enables stresses greater than the $0.2 \%$ proof stress to be achieved. The relationship between the strain ratio $\varepsilon_{c s m} / \varepsilon_{y}$, where $\varepsilon_{y}$ is the yield strain equal to $\sigma_{0.2} / E$, and the cross-section slenderness $\bar{\lambda}_{p}$, calculated as $\sqrt{\sigma_{0.2} / \sigma_{c r}}$, in which $\sigma_{c r}$ is the elastic buckling stress of the cross-section allowing for element interaction [44-45] or its most slender constituent element under the applied loading conditions, is defined by Eq. (10), where, $\varepsilon_{u}=1-\sigma_{0.2} / \sigma_{u}$ (for austenitic and duplex stainless steels) is the strain at the material ultimate tensile stress.

$$
\frac{\varepsilon_{c s m}}{\varepsilon_{y}}=\frac{0.25}{\bar{\lambda}_{p}^{3.6}} \text { but } \leq \min \left(15, \frac{0.1 \varepsilon_{u}}{\varepsilon_{y}}\right)
$$

The strain hardening modulus $E_{s h}$, employed in the CSM elastic, linear hardening material model illustrated in Fig. 12, may be determined from Eq. (11)

$$
E_{s h}=\frac{\sigma_{u}-\sigma_{0.2}}{0.16 \varepsilon_{u}-\varepsilon_{y}}
$$

Once the maximum attainable strain $\varepsilon_{c s m}$ and strain hardening modulus $E_{s h}$ have been determined, the CSM design stress can be calculated from Eq. (12).

$$
\sigma_{c s m}=\sigma_{0.2}+E_{s h}\left(\varepsilon_{c s m}-\varepsilon_{y}\right)
$$

This limiting stress $\sigma_{c s m}$ can be used directly to obtain the cross-section compression resistance $N_{c s m}$ through Eq. (13).

$$
N_{c s m}=A \sigma_{c s m}
$$


The CSM cross-section resistance in bending $M_{c s m}$ may be determined from Eq. (14) $[13,17]$, where $\gamma$ is equal to 2 for RHS bending about either principal axis.

$$
M_{c s m}=M_{p l}\left[1+\frac{E_{s h}}{E} \frac{W_{e l}}{W_{p l}}\left(\frac{\varepsilon_{c s m}}{\varepsilon_{y}}-1\right)-\left(1-\frac{W_{e l}}{W_{p l}}\right) /\left(\frac{\varepsilon_{c s m}}{\varepsilon_{y}}\right)^{\gamma}\right]
$$

The proposed CSM interaction formulae [43] for RHS under major and minor axis eccentric compression are given by Eqs (15)-(16), respectively, while the expression for biaxial bending plus compression is given in Eq. (17):

$$
\begin{aligned}
& M_{E d, y} \leq M_{R, c s m 1, y}=M_{c s m, y}\left[1-\left(\frac{N_{E d}}{N_{c s m}}\right)^{\alpha_{y}}\right]^{1 / b_{y}} \\
& M_{E d, z} \leq M_{R, c s m 1, z}=M_{c s m, z}\left[1-\left(\frac{N_{E d}}{N_{c s m}}\right)^{\alpha_{z}}\right]^{1 / b_{z}} \\
& \left(\frac{M_{E d, y}}{M_{R, c s m 1, y}}\right)^{\alpha_{c s m 1}}+\left(\frac{M_{E d, z}}{M_{R, c s m 1, z}}\right)^{\beta_{c s m 1}} \leq 1
\end{aligned}
$$

where $N_{c s m}, M_{c s m, y}$ and $M_{c s m, z}$ are the CSM compression and bending (major and minor axes) resistances, which act as the end points of the interaction curves and are calculated according to Eqs (13)-(14), $M_{R, c s m 1, y}$ and $M_{R, c s m 1, z}$ are the reduced CSM bending resistances about the major and minor axes due to the existence of the axial load $N_{E d}$; note that the ' 1 ' in the subscript signifies resistances determined on the basis of the proposals of Liew and Gardner [43], where the extent of reduction is determined by $\alpha_{y}=1.2+A_{w} / A$, $\alpha_{z}=1.2+A_{f} / A$ and $b_{y}=b_{z}=0.8, \alpha_{c s m 1}$ and $\beta_{c s m 1}$ are the interaction coefficients for biaxial bending, whose values are equal to $1.75+W_{r}\left(2 n_{c s m}^{2}-0.15\right)$ and $1.6+\left(3.5-1.5 W_{r}\right) n_{c s m}^{2}$, respectively, where $W_{r}$ is the ratio of major to minor axis plastic section moduli $W_{p l, y} / W_{p l, z}$ and $n_{c s m}$ is the ratio of design axial force to CSM compression resistance $N_{E d} / N_{c s m}$. 
Figs 13-14 present the comparisons between the CSM and EN 1993-1-4 by plotting the ratio of test (or FE) capacity to CSM predicted capacity against the cross-section slenderness $\bar{\lambda}_{p}$. The results show that the CSM yields more accurate and less scattered capacity predictions than EN 1993-1-4 (2006) [2] for both austenitic and lean duplex stainless steels. The quantitative evaluation of the CSM is reported in Tables 5-8, showing that for the austenitic grade, the mean test (or FE) to CSM resistance ratios $R_{u} / R_{u, c s m 1}$ are equal to 1.14 and 1.10 with the corresponding values of $\mathrm{COV}$ equal to $5.7 \%$ and $4.6 \%$ for uniaxial bending plus compression and biaxial bending plus compression cases, respectively. For the lean duplex grade, the mean ratios of $R_{u} / R_{u, c s m 1}$ are 1.13 and 1.12 for stub columns under uniaxial and biaxial eccentric compression, respectively, and the corresponding COVs are equal to $2.7 \%$ and 3.2\%. Compared to the European code and American Specification, considerable decreases in both the mean ratio of test (or FE) to predicted capacities and the corresponding COV are obtained using the CSM, indicating that the CSM offers substantial advantages over these codified design methods in the prediction of stainless steel cross-section resistance under combined loading, in terms of both accuracy and the consistency.

\subsection{Simplified CSM}

Figs 15-16 depict the normalised uniaxial bending plus compression test and FE results for the austenitic and lean duplex grades, respectively. Herein, the CSM compression resistance $N_{c s m}$ and bending resistance $M_{c s m}$ are employed in the normalisation, rather than the plastic bending resistance $M_{p l}$ and yield load $A \sigma_{0.2}$ as used in Figs 10-11. In contrast with the scattered normalised points in Figs 10-11, all the normalised test and FE points in Figs 15-16 converge and roughly follow a bi-linear distribution. Therefore, the new approach of adopting 
the CSM resistances $N_{c s m}, M_{c s m, y}$ and $M_{c s m, z}$ as the end points of the interaction curves but otherwise retaining the Eurocode interaction formulae and coefficients is considered. For RHS under uniaxial bending plus compression, the bi-linear format of the codified interaction curves is maintained, but with $N_{c s m}, M_{c s m, y}$ and $M_{c s m, z}$ replacing $A \sigma_{0.2}, M_{p l, y}$ and $M_{p l, z}$ as shown in Eqs (18)-(19), where $M_{R, c s m, y}$ and $M_{R, c s m, z}$ are respectively the reduced CSM bending resistances about major and minor axes due to $N_{E d}$, utilising the Eurocode form of interaction curve. The interaction formula for RHS under biaxial bending plus compression is shown in Eq. (20), in which $\alpha_{c s m}$ and $\beta_{c s m}$ are taken from Eurocode 3, but based on the CSM end points, i.e. $\alpha_{c s m}=\beta_{c s m}=1.66 /\left(1-1.13 n_{c s m}^{2}\right)$, in which $n_{c s m}=N_{E d} / N_{c s m}$.

$$
\begin{aligned}
& M_{E d, y} \leq M_{R, c s m, y}=M_{c s m, y} \frac{\left(1-n_{c s m}\right)}{\left(1-0.5 a_{w}\right)} \leq M_{c s m, y} \\
& M_{E d, z} \leq M_{R, c s m, z}=M_{c s m, z} \frac{\left(1-n_{c s m}\right)}{\left(1-0.5 a_{f}\right)} \leq M_{c s m, z} \\
& {\left[\frac{M_{E d, y}}{M_{R, c s m, y}}\right]^{\alpha_{c s m}}+\left[\frac{M_{E d, z}}{M_{R, c s m, z}}\right]^{\beta_{c s m}} \leq 1}
\end{aligned}
$$

The applicability of the simplified CSM approach is assessed by comparing the experimental and numerical results with the predicted strengths. The comparisons, as reported in Tables 58, reveal a high level of accuracy and consistency in predicting the cross-sectional resistance under combined loading. For the austenitic grade, the mean values of $R_{u} / R_{u, c s m}$ are equal to 1.10 and 1.04 , with the corresponding values of $\mathrm{COV}$ equal to $5.6 \%$ and $5.1 \%$, for uniaxial and biaxial eccentric compression cases, respectively. For the lean duplex grade, the mean $R_{u} / R_{u, c s m}$ ratios are 1.09 with the COV of $2.8 \%$ and 1.08 with the COV equal to $7.2 \%$ for stub columns under uniaxial bending plus compression and biaxial bending plus compression, respectively. Figs 17(a)-17(e) depict the uniaxial bending plus compression test results 
compared against the design interaction curves obtained from the four design methods, while a comparison of the biaxial bending plus compression test results with various interaction surfaces is shown in Fig. 18. These graphs highlight the importance of allowing for strain hardening in achieving accurate design predictions.

\subsection{Reliability analysis}

A standard reliability analysis was carried out to assess the CSM and simplified CSM, following EN 1990 Annex D [4]. The considered experimental and FE data is plotted in Figs 19-22. Tables 9-10 summarize the key statistical parameters for the CSM and simplified CSM, respectively, including the number of tests and FE simulations $n$, the design (ultimate limit state) fractile factor $k_{d, n}$, the average ratio of test (or FE) to model resistance based on a least squares fit to all the data $b$, the coefficient of variation of the tests and FE simulations relative to the resistance model $V_{\delta}$, the combined coefficient of variation incorporating both

model and basic variable uncertainties $V_{r}$, and the partial safety factor $\gamma_{M 0}$. The material overstrength was taken as 1.3 for the austenitic material and 1.1 for the lean duplex material, with the COVs of material strength were taken as 0.066 and 0.049 , respectively, in accordance with [46]. Variation in geometric properties also followed the recommendation in [46]. For both the CSM and simplified CSM, the required partial factors are all less than the currently adopted value of $\gamma_{M 0}=1.1$ used in EN 1993-1-4 (2006) [2]. This partial factor may therefore be safely applied. 


\subsection{Summary}

Overall, the American Specification offers the most conservative and scattered predictions of the resistance of stainless steel under combined loading, due to the neglect of strain hardening and the employment of linear interaction design curves. Although still conservative, the EN 1993-1-4 predictions are generally more accurate than the SEI/ASCE-8 predictions, mainly due to the adoption of nonlinear interaction curves for class 1 and 2 cross-sections. As shown in Tables 5-8, the CSM leads to very good predictions and lower scatter; the simplified CSM also results in very good predictions, but with slightly increased scatter. For both the CSM and simplified CSM, the scatter is generally less than half that of existing codified methods.

\section{Conclusions}

A comprehensive numerical modelling programme has been performed initially to replicate the experimental results reported in the companion paper [1]. Upon validation of the FE models, a series of parametric studies was carried out to expand the experimental data over a wider range of cross-section slenderness. Analysis of the experimental and numerical results allowed the applicability of the design provisions of EN 1993-1-4 (2006) [2] and SEI/ASCE8 (2002) [3] to be assessed. Generally, the codified methods significantly under-estimate the actual cross-sectional resistance under combined loading, mainly owing to the lack of consideration for strain hardening. The Continuous Strength Method (CSM) is a deformationbased design approach which relates the strength of a cross-section to its deformation capacity and employs a bi-linear material model to allow a rational exploitation of strain hardening and more efficient design rules. The approach of using the CSM compression and 
bending resistances as the end points for the Eurocode interaction curves was shown to provide accurate predictions of the resistance of stainless steel cross-sections under combined loading. The reliability of such an approach was demonstrated through a statistical analysis according to EN 1990 Annex D [4], and it is recommended that the proposed approach is considered for incorporation into future revisions of EN 1993-1-4 and other international design codes for stainless steel.

\section{Acknowledgements}

The authors gratefully acknowledge the Joint PhD Scholarship and Dixon Scholarship from Imperial College London for the financial support.

\section{References}

[1] Zhao O, Rossi B, Gardner L, Young B. Behaviour of structural stainless steel crosssections under combined loading - Part I: Experimental study.

[2] EN 1993-1-4. Eurocode 3: Design of steel structures - Part 1.4: General rules Supplementary rules for stainless steels. Brussels: European Committee for Standardization (CEN); 2006.

[3] SEI/ASCE 8-02. Specification for the design of cold-formed stainless steel structural members. Reston: American Society of Civil Engineers (ASCE); 2002.

[4] EN 1990. Eurocode - basis of structural design. Brussels: European Committee for Standardization (CEN); 2002. 
[5] Gardner L, Nethercot DA. Experiments on stainless steel hollow sections - Part 1: Material and cross-sectional behaviour. Journal of Constructional Steel Research, 2004;60(9):1291-318.

[6] Gardner L, Nethercot DA. Experiments on stainless steel hollow sections - Part 2: Member behaviour of columns and beams. Journal of Constructional Steel Research, 2004;60(9):1319-32.

[7] Real E, Mirambell E. Flexural behaviour of stainless steel beams. Engineering Structures, 2005;27(10):1465-75.

[8] Theofanous M, Gardner L. Testing and numerical modelling of lean duplex stainless steel hollow section columns. Engineering Structures, 2009;31(12):3047-58.

[9] Theofanous M, Gardner L. Experimental and numerical studies of lean duplex stainless steel beams. Journal of Constructional Steel Research, 2010;66(6):816-25.

[10] Huang Y, Young B. Experimental and numerical investigation of cold-formed lean duplex stainless steel flexural members. Thin-Walled Structures, 2013;73(19):216-28.

[11] Huang Y, Young B. Tests of pin-ended cold-formed lean duplex stainless steel columns. Journal of Constructional Steel Research, 2013;82:203-15.

[12] Huang Y, Young B. Experimental investigation of cold-formed lean duplex stainless steel beam-columns. Thin-Walled Structures, 2014;76:105-17.

[13] AISC Design Guide 30: Structural Stainless Steel. American Institute of Steel Construction; 2012. 
[14] AS/NZS 4673:2001. Cold-formed stainless steel structures. Sydney: Standards Australia; 2001.

[15] Gardner L. A new approach to structural stainless steel design. PhD Thesis. UK: Imperial College London; 2002.

[16] Ashraf M, Gardner L, Nethercot DA. Structural stainless steel design: resistance based on deformation capacity. Journal of Structural Engineering (ASCE), 2008;134(3):402-11.

[17] Afshan S, Gardner L. The continuous strength method for structural stainless steel design. Thin-Walled Structures, 2013;68(4):42-49.

[18] Schafer BW. Review: the direct strength method of cold-formed steel member design. Journal of Constructional Steel Research, 2008;64(7):766-78.

[19] Becque J, Lecce M, Rasmussen KJR. The direct strength method for stainless steel compression members. Journal of Constructional Steel Research, 2008;64(11):1231-38.

[20] Lopes N, Vila Real P, Simões da Silva L. Numerical modelling of the flexural buckling of axially loaded stainless steel members. Proceedings of the Third International Conference on Steel and Composite Structures, pp. 237-42, Manchester, United Kingdom; 2007.

[21] Hradil P, Talja A. Numerical verification of stainless steel overall buckling curves. ThinWalled Structures, in press.

[22] Greiner R, Kettler M. Interaction of bending and axial compression of stainless steel members. Journal of Constructional Steel Research, 2008;64(11):1217-24. 
[23] Lopes N, Vila Real P, Simões da Silva L. Stainless steel beam-columns interaction curves with and without lateral torsional buckling. Proceedings of the 7th EUROMECH Solid Mechanics Conference, Lisbon, Portugal; 2009.

[24] Huang Y, Young B. Design of cold-formed lean duplex stainless steel members in compression and bending. Journal of Structural Engineering (ASCE), In press.

[25] Hibbitt, Karlsson \& Sorensen, Inc. ABAQUS. ABAQUS/Standard user's manual volumes I-III and ABAQUS CAE manual. Version 6.12. Pawtucket (USA); 2012.

[26] Gardner L, Nethercot DA. Numerical modeling of stainless steel structural components A consistent approach. Journal of Structural Engineering (ASCE), 2004;130(10):1586-601.

[27] Gardner L, Ashraf M. Structural design for non-linear metallic materials. Engineering Structures, 2006;28(6):926-34.

[28] Ramberg W, Osgood WR. Description of stress-strain curves by three parameters. Technical note No 902, Washington DC: National advisory committee for aeronautics. 1943.

[29] Hill HN. Determination of stress-strain relations from offset yield strength values. Technical note No 927, Washington DC: National advisory committee for aeronautics. 1944.

[30] Mirambell E, Real E. On the calculation of deflections in structural stainless steel beams: An experimental and numerical investigation. Journal of Constructional Steel Research, 2000;54(1):109-33.

[31] Rasmussen KJR. Full-range stress-strain curves for stainless steel alloys. Journal of Constructional Steel Research, 2003;59(1):47-61. 
[32] Cruise RB, Gardner L. Strength enhancements induced during cold forming of stainless steel sections. Journal of Constructional Steel Research, 2008;64(11):1310-6.

[33] Afshan S, Rossi B, Gardner L. Strength enhancements in cold-formed structural sections - Part I: Material testing, Journal of Constructional Steel Research, 2013;83(16):177-88.

[34] Ashraf M, Gardner L, Nethercot DA. Finite element modelling of structural stainless steel cross-sections. Thin-Walled Structures, 2006;44(10):1048-62.

[35] Cruise RB, Gardner L. Residual stress analysis of structural stainless steel sections. Journal of Constructional Steel Research, 2008;64(3):352-66.

[36] Huang Y, Young B. Material properties of cold-formed lean duplex stainless steel sections. Thin-Walled Structures, 2012;54(7):72-81.

[37] Jandera M, Gardner L, Machacek J. Residual stresses in cold-rolled stainless steel hollow sections. Journal of Constructional Steel Research, 2008;64(11):1255-63.

[38] Rasmussen KJR, Hancock GJ. Design of cold-formed stainless steel tubular members. I: Columns. Journal of Structural Engineering (ASCE), 1993;119(8):2349-67.

[39] Silvestre N, Camotim D, Dinis PB. Post-buckling behaviour and direct strength design of lipped channel columns experiencing local/distortional interaction. Journal of Constructional Steel Research, 2012;73:12-30.

[40] Hassanein MF, Silvestre N. Flexural behavior of lean duplex stainless steel girders with slender unstiffened webs. Journal of Constructional Steel Research, 2013;85:12-23. 
[41] Dawson RG, Walker AC. Post-buckling of geometrically imperfect plates. Journal of the Structural Division (ASCE), 1972;98(1):75-94.

[42] EN 1993-1-1. Eurocode 3: Design of steel structures - Part 1.1: General rules and rules for buildings. Brussels: European Committee for Standardization (CEN); 2005.

[43] Liew A, Gardner L. Ultimate capacity of structural steel cross-sections under combined loading. Structures, submitted.

[44] Schafer BW, Ádány S. Buckling analysis of cold-formed steel members using CUFSM: conventional and constrained finite strip methods. Eighteenth International Specialty Conference on Cold-formed Steel Structures, pp. 39-54, Orlando, USA; 2006.

[45] Theofanous M, Gardner L. Effect of element interaction and material nonlinearity on the ultimate capacity of stainless steel cross-sections. Steel and Composite Structures, 2012;12(1):73-92.

[46] Baddoo N, Francis P. Re-evaluation of EN 1993-1-4 partial resistance factors. SCI report RT1533. The Steel Construction Institute; 2013. 
Table 1 Comparison of the stub column test results with FE results for varying imperfection amplitudes.

\begin{tabular}{|c|c|c|c|c|c|c|c|}
\hline \multirow[t]{2}{*}{ Cross-section } & \multirow[t]{2}{*}{ Specimen ID } & \multicolumn{2}{|c|}{ Measured amplitude } & \multicolumn{2}{|c|}{$t / 100$} & \multicolumn{2}{|c|}{ Dawson and Walker model } \\
\hline & & $\mathrm{FE} \mathrm{N}_{\mathrm{u}} /$ Test $\mathrm{N}_{\mathrm{u}}$ & FE $\delta_{\mathrm{u}} /$ Test $\delta_{\mathrm{u}}$ & FE $N_{u} /$ Test $N_{u}$ & FE $\delta_{\mathrm{u}} /$ Test $\delta_{\mathrm{u}}$ & $\mathrm{FE} \mathrm{N}_{\mathrm{u}} /$ Test $\mathrm{N}_{\mathrm{u}}$ & $\mathrm{FE} \delta_{\mathrm{u}} /$ Test $\delta_{\mathrm{u}}$ \\
\hline SHS $100 \times 100 \times 5$ & $1 \mathrm{~A}$ & 0.96 & 1.00 & 0.94 & 0.79 & 0.95 & 0.86 \\
\hline SHS $120 \times 120 \times 5$ & $2 \mathrm{~A}$ & 0.98 & 0.95 & 0.98 & 0.93 & 0.98 & 0.95 \\
\hline RHS $150 \times 100 \times 6$ & $3 \mathrm{~A}$ & 0.99 & 0.92 & 0.99 & 0.92 & 0.99 & 0.92 \\
\hline RHS $150 \times 100 \times 8$ & $4 \mathrm{~A}$ & 1.03 & 0.99 & 1.03 & 0.97 & 1.03 & 0.99 \\
\hline SHS $150 \times 150 \times 8$ & $5 \mathrm{~A}$ & 1.01 & 0.90 & 0.99 & 0.78 & 1.01 & 0.92 \\
\hline Mean & & 0.99 & 0.95 & 0.99 & 0.88 & 0.99 & 0.93 \\
\hline $\mathrm{COV}$ & & 0.03 & 0.04 & 0.03 & 0.09 & 0.03 & 0.05 \\
\hline
\end{tabular}

Table 2 Comparison of the four-point bending test results with FE results for varying imperfection amplitudes.

\begin{tabular}{|c|c|c|c|c|c|c|c|}
\hline \multirow[t]{2}{*}{ Cross-section } & \multirow[t]{2}{*}{ Specimen ID } & \multicolumn{2}{|c|}{ Measured amplitude } & \multicolumn{2}{|c|}{$t / 100$} & \multicolumn{2}{|c|}{ Dawson and Walker model } \\
\hline & & $\mathrm{FE} \mathrm{M}_{\mathrm{u}} /$ Test $\mathrm{M}_{\mathrm{u}}$ & $\mathrm{FE} \kappa_{\mathrm{u}} /$ Test $\kappa_{\mathrm{u}}$ & $\mathrm{FE} \mathrm{M}_{\mathrm{u}} /$ Test $\mathrm{M}_{\mathrm{u}}$ & FE $\kappa_{\mathrm{u}} /$ Test $\kappa_{\mathrm{u}}$ & FE $\mathrm{M}_{\mathrm{u}} /$ Test $\mathrm{M}_{\mathrm{u}}$ & FE $\kappa_{\mathrm{u}} /$ Test $\kappa_{\mathrm{u}}$ \\
\hline SHS $100 \times 100 \times 5$ & 1B & 0.93 & 1.10 & 0.93 & 1.01 & 0.93 & 1.04 \\
\hline SHS $120 \times 120 \times 5$ & $2 \mathrm{~B}$ & 0.96 & 1.07 & 0.96 & 1.14 & 0.96 & 1.14 \\
\hline RHS $150 \times 100 \times 6$ & 3B & 1.02 & 1.28 & 1.02 & 1.28 & 1.02 & 1.30 \\
\hline RHS $150 \times 100 \times 8$ & $4 \mathrm{~B}$ & 1.06 & 1.05 & 1.06 & 1.00 & 1.06 & 1.10 \\
\hline SHS $150 \times 150 \times 8$ & $5 \mathrm{~B}$ & 1.04 & 1.09 & 1.03 & 1.07 & 1.04 & 1.13 \\
\hline Mean & & 1.00 & 1.12 & 1.00 & 1.10 & 1.00 & 1.14 \\
\hline $\mathrm{COV}$ & & 0.05 & 0.09 & 0.05 & 0.12 & 0.05 & 0.10 \\
\hline
\end{tabular}


Table 3 Comparison of the uniaxial eccentric compression test results with FE results for varying imperfection amplitudes.

\begin{tabular}{|c|c|c|c|c|c|c|c|c|}
\hline \multirow[t]{2}{*}{ Cross-section } & \multirow[t]{2}{*}{ Specimen ID } & \multirow{2}{*}{$\begin{array}{c}\mathrm{e}_{0} \\
(\mathrm{~mm})\end{array}$} & \multicolumn{2}{|c|}{ Measured amplitude } & \multicolumn{2}{|c|}{$\mathrm{t} / 100$} & \multicolumn{2}{|c|}{ Dawson and Walker model } \\
\hline & & & FE $N_{u} /$ Test $N_{u}$ & $\mathrm{FE} \phi_{\mathrm{u}} / \mathrm{Test} \phi_{\mathrm{u}}$ & $\mathrm{FE} \mathrm{N}_{\mathrm{u}} /$ Test $\mathrm{N}_{\mathrm{u}}$ & $\mathrm{FE} \phi_{\mathrm{u}} / \mathrm{Test} \phi_{\mathrm{u}}$ & FE $N_{u} /$ Test $N_{u}$ & FE $\phi_{u} /$ Test $\phi_{u}$ \\
\hline \multirow{4}{*}{ SHS $100 \times 100 \times 5$} & $1 \mathrm{C}$ & 17.9 & 0.94 & 1.07 & 0.95 & 1.08 & 0.95 & 1.10 \\
\hline & $1 \mathrm{D}$ & 25.8 & 1.00 & 1.03 & 1.00 & 1.04 & 1.00 & 1.04 \\
\hline & $1 \mathrm{E}$ & 52.9 & 0.95 & 0.99 & 0.96 & 1.03 & 0.96 & 1.04 \\
\hline & $1 \mathrm{~F}$ & 120.0 & - & - & - & - & - & - \\
\hline \multirow{4}{*}{ SHS $120 \times 120 \times 5$} & $2 \mathrm{C}$ & 10.0 & 0.97 & 1.03 & 0.98 & 1.13 & 0.98 & 1.13 \\
\hline & $2 \mathrm{D}$ & 38.0 & 0.98 & 1.00 & 1.00 & 1.12 & 1.00 & 1.12 \\
\hline & $2 \mathrm{E}$ & 68.0 & 0.96 & 0.93 & 0.97 & 0.94 & 0.98 & 1.03 \\
\hline & $2 \mathrm{~F}$ & 120.0 & 0.95 & - & 0.96 & - & 0.97 & - \\
\hline \multirow{4}{*}{ RHS $150 \times 100 \times 6$} & $3 \mathrm{C}$ & 44.8 & 0.99 & 1.11 & 0.99 & 1.12 & 0.99 & 1.10 \\
\hline & $3 \mathrm{D}$ & 64.1 & 1.01 & 0.91 & 1.01 & 0.92 & 1.01 & 0.92 \\
\hline & $3 \mathrm{E}$ & 92.4 & 1.00 & 1.05 & 1.00 & 1.08 & 1.00 & 1.12 \\
\hline & $3 \mathrm{~F}$ & 128.4 & 0.98 & 1.00 & 0.98 & 1.03 & 0.98 & 1.02 \\
\hline \multirow{4}{*}{ RHS $150 \times 100 \times 8$} & $4 \mathrm{C}$ & 19.9 & 0.99 & 1.09 & 0.99 & 1.04 & 0.99 & 1.11 \\
\hline & $4 \mathrm{D}$ & 51.6 & 0.99 & 1.04 & 0.98 & 0.99 & 0.99 & 1.05 \\
\hline & $4 \mathrm{E}$ & 75.0 & 1.01 & 0.95 & 1.01 & 0.90 & 1.01 & 0.94 \\
\hline & $4 \mathrm{~F}$ & 140.0 & - & - & - & - & - & - \\
\hline \multirow{4}{*}{ SHS $150 \times 150 \times 8$} & $5 \mathrm{C}$ & 29.5 & 1.02 & 1.08 & 1.01 & 0.90 & 1.01 & 0.99 \\
\hline & $5 \mathrm{D}$ & 51.6 & 1.00 & 1.01 & 1.00 & 0.85 & 1.00 & 0.94 \\
\hline & $5 \mathrm{E}$ & 84.2 & 1.02 & 1.00 & 1.01 & 0.80 & 1.01 & 0.87 \\
\hline & $5 \mathrm{~F}$ & 116.4 & 0.99 & - & 0.98 & - & 0.99 & - \\
\hline Mean & & & 0.99 & 1.02 & 0.99 & 1.00 & 0.99 & 1.03 \\
\hline $\mathrm{COV}$ & & & 0.02 & 0.06 & 0.02 & 0.10 & 0.02 & 0.08 \\
\hline
\end{tabular}

Table 4 Comparison of the biaxial eccentric compression test results with FE results for varying imperfection amplitudes.

\begin{tabular}{|c|c|c|c|c|c|c|c|c|c|c|c|c|}
\hline \multirow[t]{2}{*}{ Section } & \multirow[t]{2}{*}{ Specimen ID } & \multirow{2}{*}{$\begin{array}{c}\mathrm{e}_{0 \mathrm{y}} \\
(\mathrm{mm})\end{array}$} & \multirow{2}{*}{$\begin{array}{c}\mathrm{e}_{0 z} \\
(\mathrm{~mm})\end{array}$} & \multicolumn{3}{|c|}{ Measured amplitude } & \multicolumn{3}{|c|}{$t / 100$} & \multicolumn{3}{|c|}{ Dawson and Walker model } \\
\hline & & & & $\begin{array}{l}\text { FE N } / \\
\text { Test } N_{u} \\
\end{array}$ & $\begin{array}{l}\text { FE } \phi_{\text {uy }} / \\
\text { Test } \phi_{\text {uy }}\end{array}$ & $\begin{array}{l}\text { FE } \phi_{\mathrm{uz}} / \\
\text { Test } \phi_{\mathrm{uz}}\end{array}$ & $\begin{array}{l}\text { FE } N_{\mathrm{u}} / \\
\text { Test } \mathrm{N}_{\mathrm{u}}\end{array}$ & $\begin{array}{l}\text { FE } \phi_{\text {uy }} / \\
\text { Test } \phi_{\text {uy }}\end{array}$ & $\begin{array}{l}\text { FE } \phi_{\mathrm{uz}} / \\
\text { Test } \phi_{\mathrm{uz}}\end{array}$ & $\begin{array}{l}\text { FE } N_{\mathrm{u}} / \\
\text { Test } \mathrm{N}_{\mathrm{u}} \\
\end{array}$ & $\begin{array}{l}\text { FE } \phi_{\text {uy }} \\
\text { Test } \phi_{\text {uy }}\end{array}$ & $\begin{array}{l}\text { FE } \phi_{\mathrm{uz}} / \\
\text { Test } \phi_{\mathrm{uz}}\end{array}$ \\
\hline \multirow{4}{*}{$\begin{array}{c}\text { SHS } \\
100 \times 100 \times 5\end{array}$} & $1 \mathrm{G}$ & 20.0 & 20.0 & 0.99 & 0.90 & 0.90 & 1.00 & 0.98 & 0.98 & 1.00 & 1.00 & 1.00 \\
\hline & $1 \mathrm{H}$ & 23.0 & 43.0 & 0.99 & 0.96 & 1.04 & 0.99 & 1.02 & 1.09 & 1.00 & 1.06 & 1.12 \\
\hline & $1 \mathrm{I}$ & 20.0 & 60.0 & 0.95 & 0.88 & 0.81 & 0.96 & 0.94 & 0.86 & 0.96 & 0.95 & 0.87 \\
\hline & $1 \mathrm{~J}$ & 23.0 & 78.0 & 0.96 & 0.88 & 0.92 & 0.96 & 0.94 & 0.97 & 0.96 & 0.96 & 0.99 \\
\hline Mean & & & & 0.97 & 0.91 & 0.92 & 0.98 & 0.97 & 0.98 & 0.98 & 0.99 & 0.99 \\
\hline $\mathrm{COV}$ & & & & 0.02 & 0.04 & 0.09 & 0.02 & 0.04 & 0.09 & 0.02 & 0.05 & 0.10 \\
\hline
\end{tabular}


Table 5 Comparison of the uniaxial bending plus compression test and FE results of austenitic stainless steel with the predicted strengths.

\begin{tabular}{ccccc}
\hline $\begin{array}{c}\text { No. of tests: 22 } \\
\text { No. of FE simulations: } 90\end{array}$ & $\mathrm{R}_{\mathrm{u}} / \mathrm{R}_{\mathrm{u}, \mathrm{EC} 3}$ & $\mathrm{R}_{\mathrm{u}} / \mathrm{R}_{\mathrm{u}, \mathrm{ASCE}}$ & $\mathrm{R}_{\mathrm{u}} / \mathrm{R}_{\mathrm{u}, \mathrm{ssm} 1}$ & $\mathrm{R}_{\mathrm{u}} / \mathrm{R}_{\mathrm{u}, \mathrm{csm}}$ \\
\hline Mean & 1.31 & 1.42 & 1.14 & 1.10 \\
COV & $10.5 \%$ & $15.8 \%$ & $5.7 \%$ & $5.6 \%$ \\
\hline
\end{tabular}

Table 6 Comparison of the biaxial bending plus compression test and FE results of austenitic stainless steel with the predicted strengths.

\begin{tabular}{ccccc}
\hline $\begin{array}{c}\text { No. of tests: } 4 \\
\text { No. of FE simulations: } 55\end{array}$ & $\mathrm{R}_{\mathrm{u}} / \mathrm{R}_{\mathrm{u}, \mathrm{EC} 3}$ & $\mathrm{R}_{\mathrm{u}} / \mathrm{R}_{\mathrm{u}, \mathrm{ASCE}}$ & $\mathrm{R}_{\mathrm{u}} / \mathrm{R}_{\mathrm{u}, \mathrm{csm} 1}$ & $\mathrm{R}_{\mathrm{u}} / \mathrm{R}_{\mathrm{u}, \mathrm{csm}}$ \\
\hline Mean & 1.24 & 1.76 & 1.10 & 1.04 \\
COV & $13.9 \%$ & $13.6 \%$ & $4.6 \%$ & $5.1 \%$ \\
\hline
\end{tabular}

Table 7 Comparison of the uniaxial bending plus compression test and FE results of lean duplex stainless steel with the predicted strengths.

\begin{tabular}{ccccc}
\hline $\begin{array}{c}\text { No. of tests: 6 } \\
\text { No. of FE simulations: 65 }\end{array}$ & $\mathrm{R}_{\mathrm{u}} / \mathrm{R}_{\mathrm{u}, \mathrm{EC} 3}$ & $\mathrm{R}_{\mathrm{u}} / \mathrm{R}_{\mathrm{u}, \mathrm{ASCE}}$ & $\mathrm{R}_{\mathrm{u}} / \mathrm{R}_{\mathrm{u}, \mathrm{csm} 1}$ & $\mathrm{R}_{\mathrm{u}} / \mathrm{R}_{\mathrm{u}, \mathrm{csm}}$ \\
\hline Mean & 1.21 & 1.34 & 1.13 & 1.09 \\
COV & $8.4 \%$ & $10.6 \%$ & $2.7 \%$ & $2.8 \%$ \\
\hline
\end{tabular}

Table 8 Comparison of the biaxial bending plus compression test and FE results of lean duplex stainless steel with the predicted strengths.

\begin{tabular}{ccccc}
\hline $\begin{array}{c}\text { No. of tests: } 0 \\
\text { No. of FE simulations: } 25\end{array}$ & $\mathrm{R}_{\mathrm{u}} / \mathrm{R}_{\mathrm{u}, \mathrm{EC} 3}$ & $\mathrm{R}_{\mathrm{u}} / \mathrm{R}_{\mathrm{u}, \mathrm{ASCE}}$ & $\mathrm{R}_{\mathrm{u}} / \mathrm{R}_{\mathrm{u}, \mathrm{ssm} 1}$ & $\mathrm{R}_{\mathrm{u}} / \mathrm{R}_{\mathrm{u}, \mathrm{ssm}}$ \\
\hline Mean & 1.23 & 1.60 & 1.12 & 1.08 \\
COV & $14.2 \%$ & $20.8 \%$ & $3.2 \%$ & $7.2 \%$ \\
\hline
\end{tabular}


Table 9 Summary of reliability analysis results for the CSM.

\begin{tabular}{ccccccc}
\hline Grade & No. of tests and FE simulations & $\mathrm{k}_{\mathrm{d}, \mathrm{n}}$ & $\mathrm{b}$ & $\mathrm{V}_{\delta}$ & $\mathrm{V}_{\mathrm{r}}$ & $\gamma_{\mathrm{M} 0}$ \\
\hline Austenitic & 171 & 3.148 & 1.125 & 0.046 & 0.095 & 0.92 \\
Lean duplex & 96 & 3.206 & 1.136 & 0.024 & 0.074 & 0.99 \\
\hline
\end{tabular}

Table 10 Summary of reliability analysis results for the simplified CSM.

\begin{tabular}{ccccccc}
\hline Grade & No. of tests and FE simulations & $\mathrm{k}_{\mathrm{d}, \mathrm{n}}$ & $\mathrm{b}$ & $\mathrm{V}_{\delta}$ & $\mathrm{V}_{\mathrm{r}}$ & $\gamma_{\mathrm{M} 0}$ \\
\hline Austenitic & 171 & 3.148 & 1.093 & 0.060 & 0.102 & 0.97 \\
Lean duplex & 96 & 3.206 & 1.099 & 0.040 & 0.081 & 1.05 \\
\hline
\end{tabular}




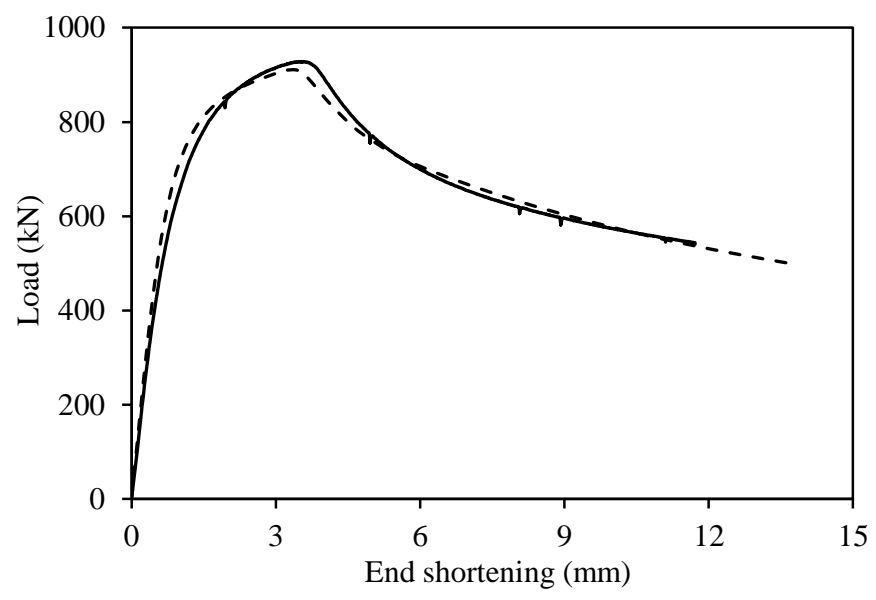

Fig. 1. Experimental and numerical load-end shortening curves for stub column specimen SHS $100 \times 100 \times 5-1 \mathrm{~A}$.

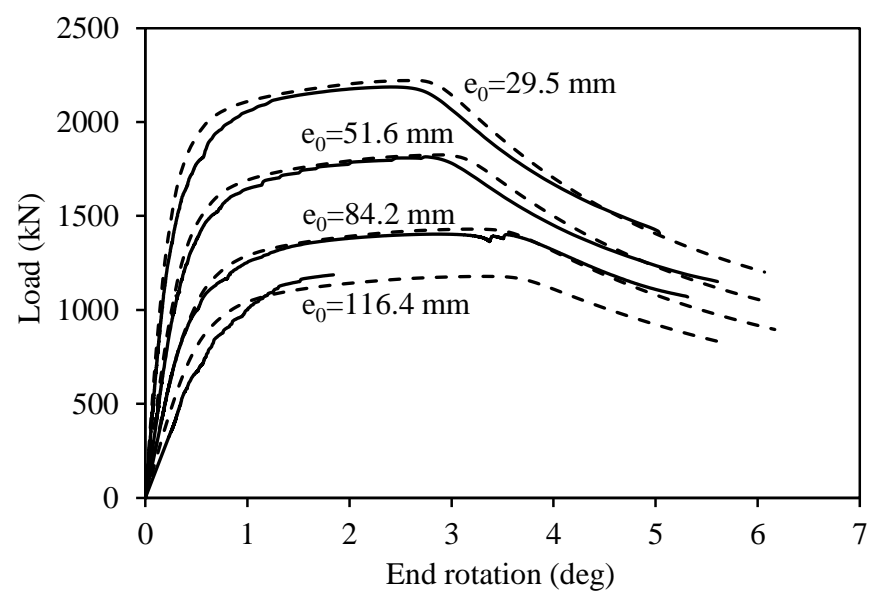

Fig. 3. Experimental and numerical load-end rotation curves for SHS $150 \times 150 \times 8$ under uniaxial bending plus compression (Specimens: $5 \mathrm{C}$ to $5 \mathrm{~F}$ ).

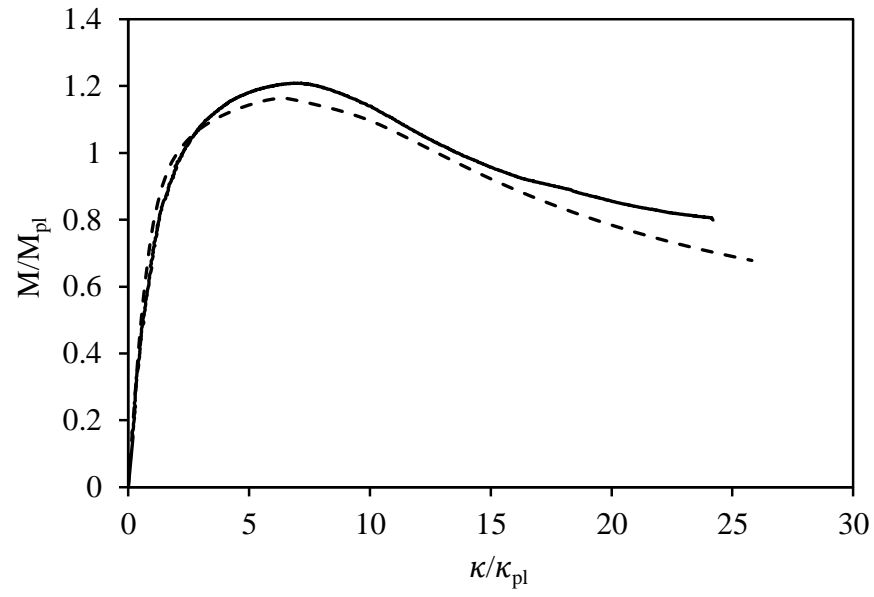

Fig. 2. Experimental and numerical normalized moment-curvature curves for four-point bending specimen SHS $100 \times 100 \times 5-1 \mathrm{~B}$.

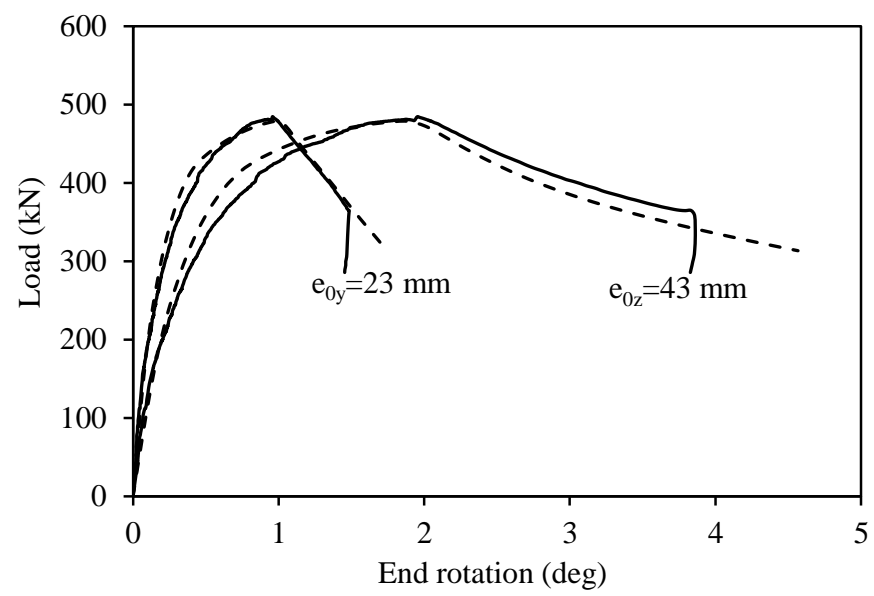

Fig. 4. Experimental and numerical load-end rotation curves for specimen SHS $100 \times 100 \times 5-1 \mathrm{H}$ under biaxial bending plus compression 

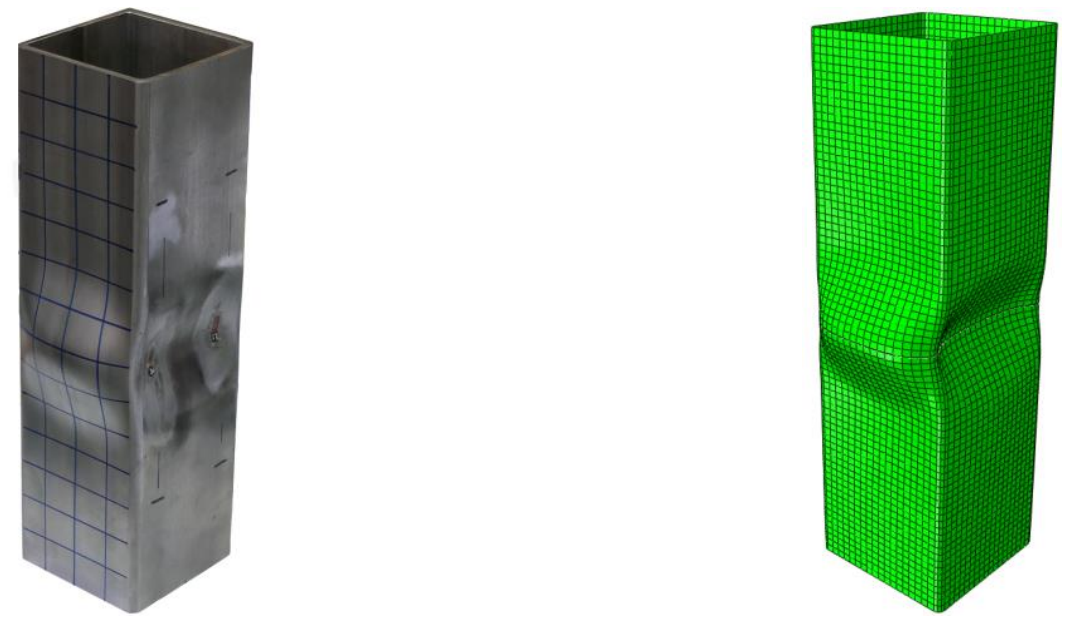

Fig. 5. Experimental and numerical failure modes for stub column specimen SHS $100 \times 100 \times 5-1 \mathrm{~A}$.

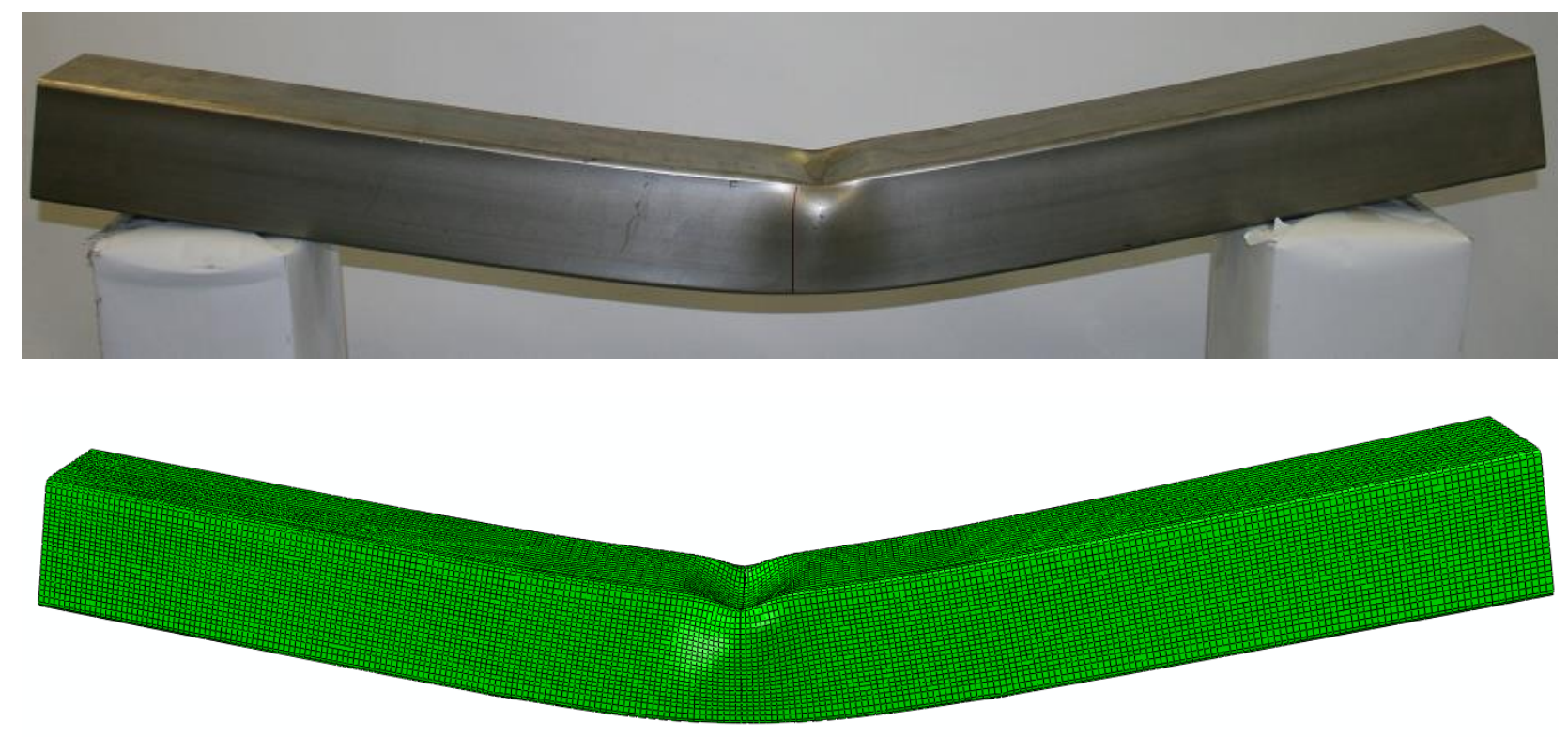

Fig. 6. Experimental and numerical failure modes for four-point bending specimen SHS $100 \times 100 \times 5-1 B$. 

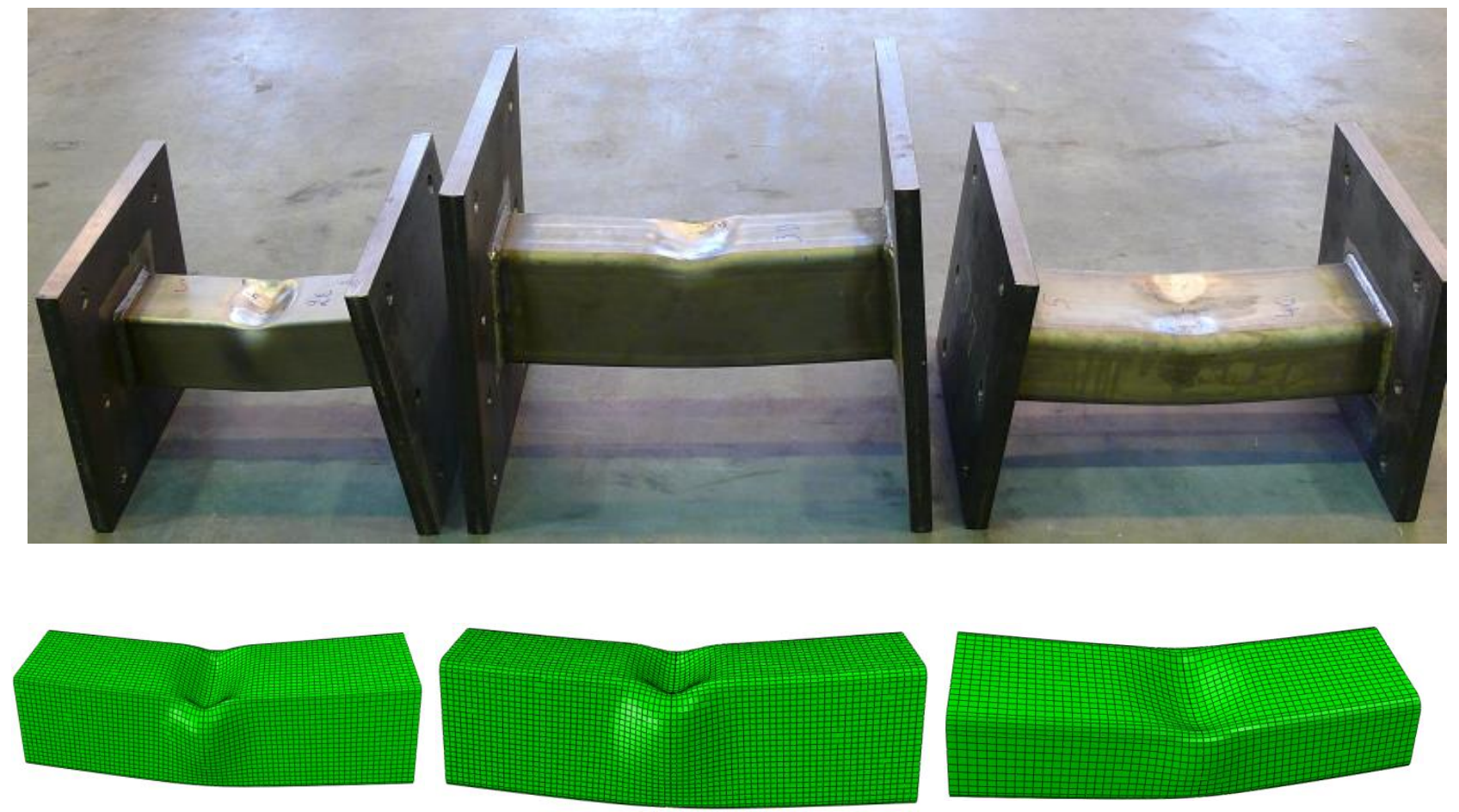

Fig. 7. Experimental and numerical failure modes for specimens under uniaxial bending plus compression (from left to right: SHS $100 \times 100 \times 5-1$ D, RHS $150 \times 100 \times 6-3$ D, RHS $150 \times 100 \times 8-4$ D).
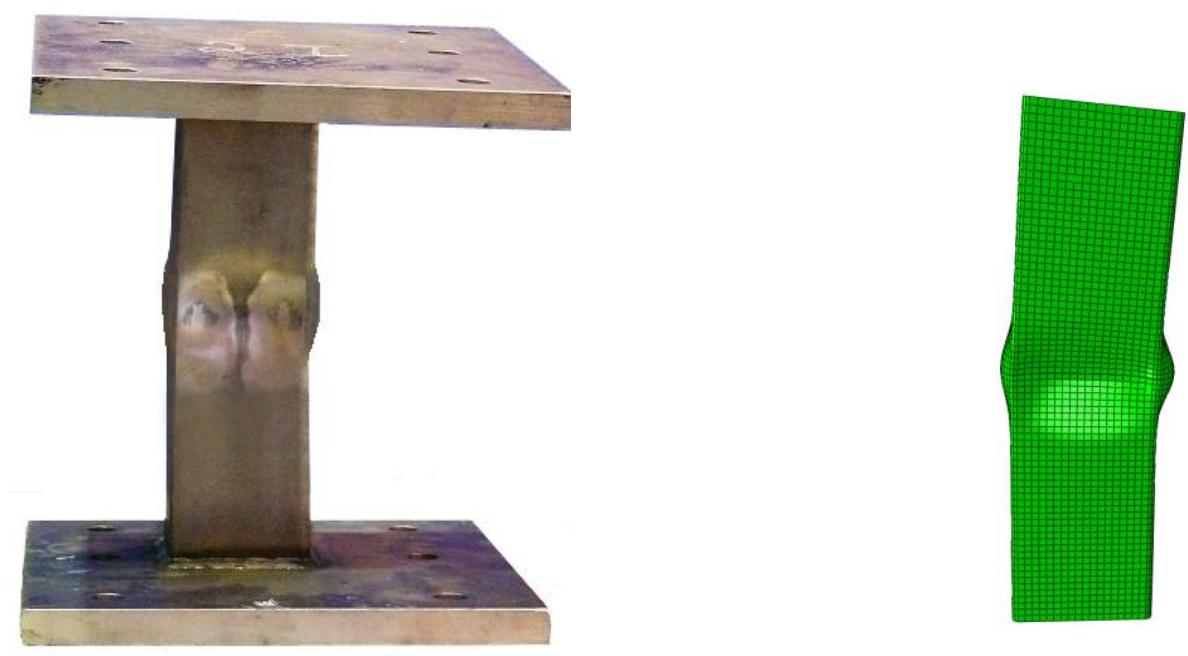

Fig. 8. Experimental and numerical failure modes for specimen SHS $100 \times 100 \times 5-1 \mathrm{H}$ under biaxial bending plus compression. 


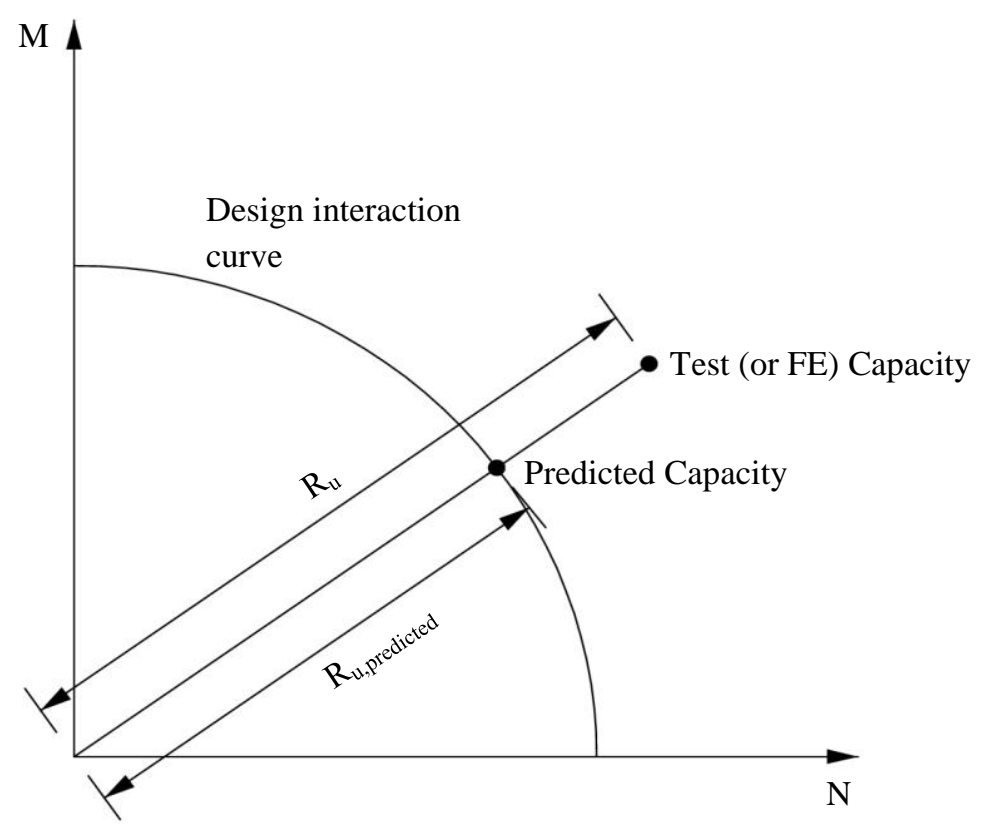

Fig. 9. Definition of $R_{u}$ and $R_{u, p r e d i c t e d}$.

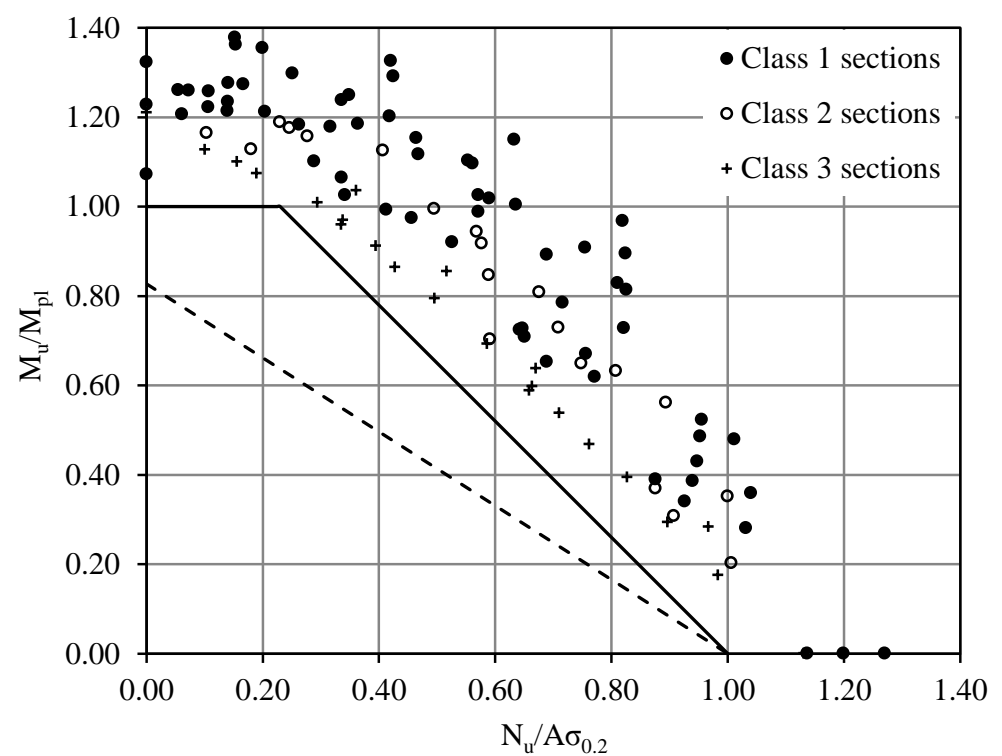

Fig. 10. Normalised austenitic stainless steel combined loading test and FE results by the plastic moment capacity and yield load (i.e. the EC3 provisions for class 1 and 2 cross-sections). 


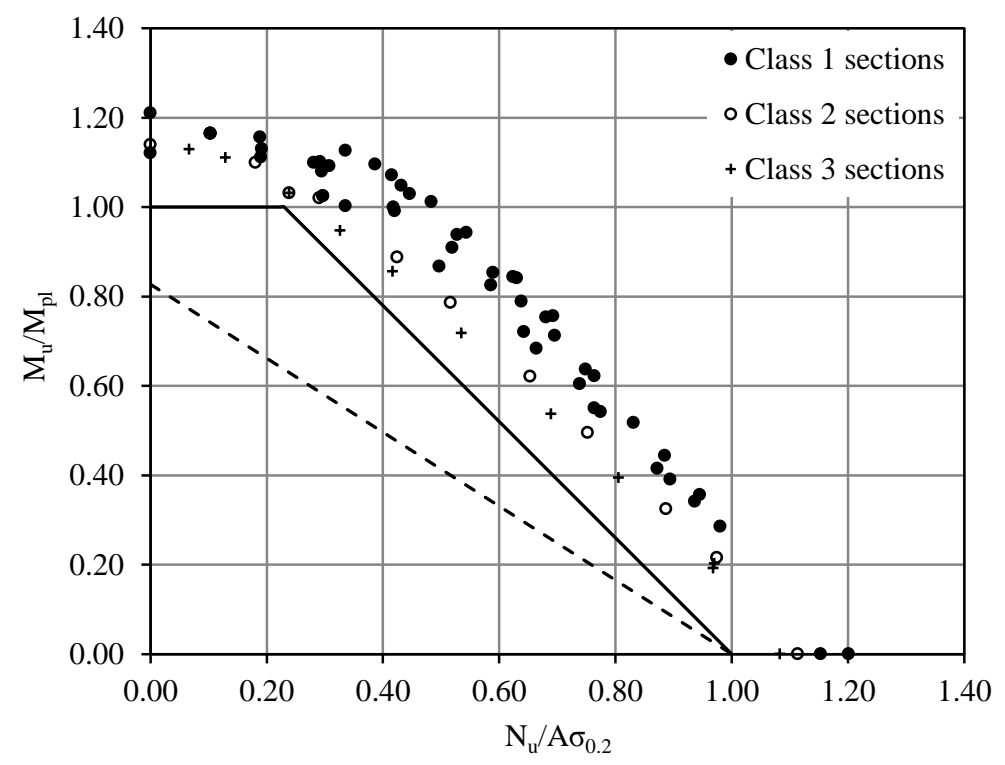

Fig. 11. Normalised lean duplex stainless steel combined loading test and FE results by the plastic moment capacity and yield load (i.e. the EC3 provisions for class 1 and 2 cross-sections).

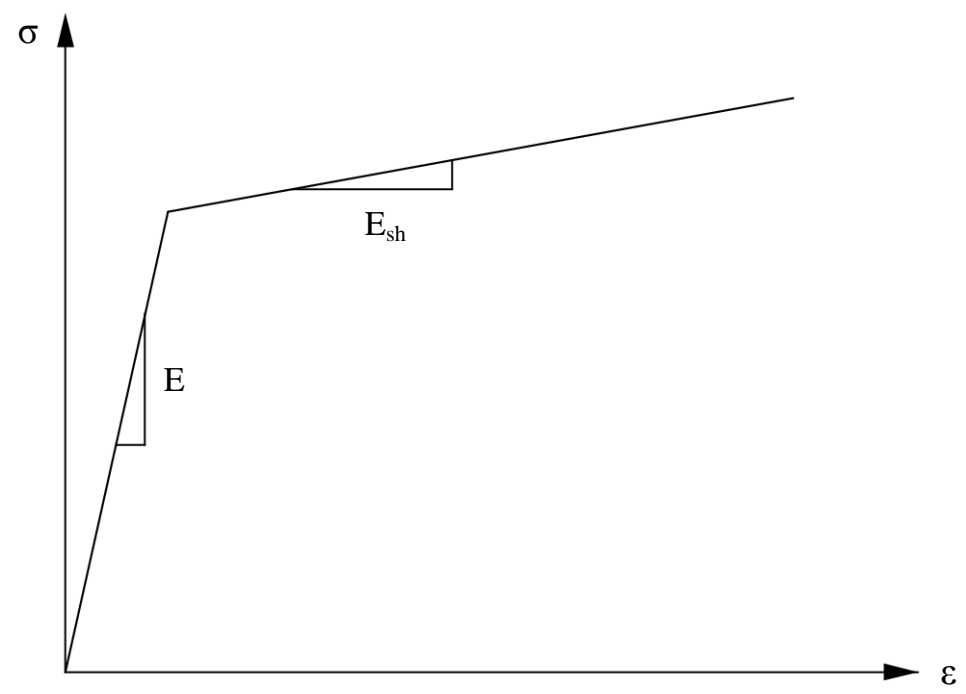

Fig. 12. CSM elastic, linear hardening material model. 


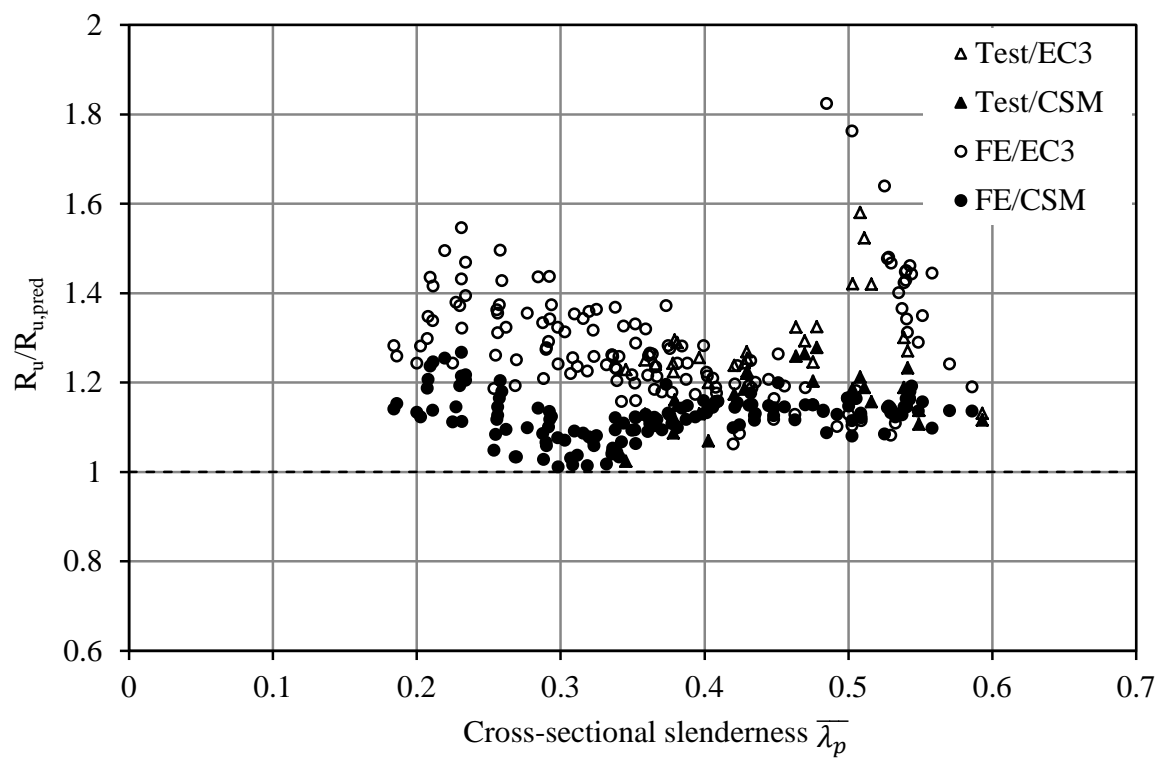

Fig. 13. Comparison of austenitic stainless steel combined loading test and FE results with the CSM and EN 1993-1-4 predictions.

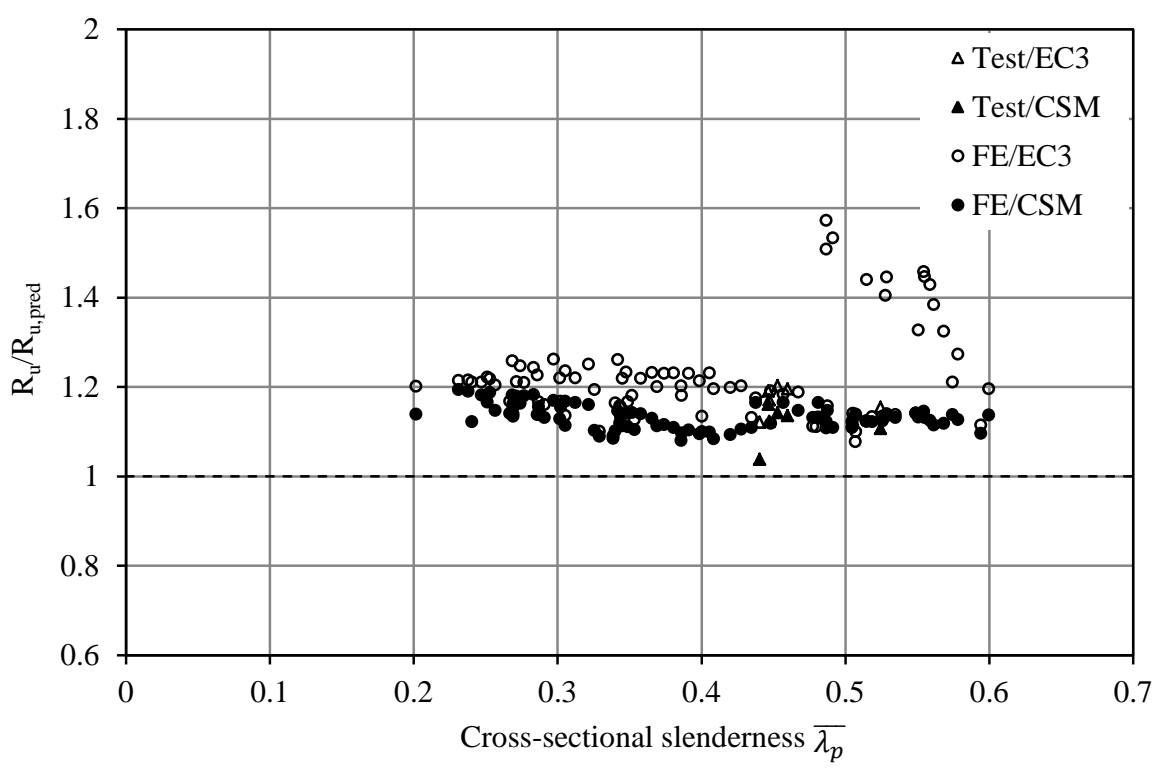

Fig. 14. Comparison of lean duplex stainless steel combined loading test and FE results with the CSM and EN 1993-1-4 predictions. 


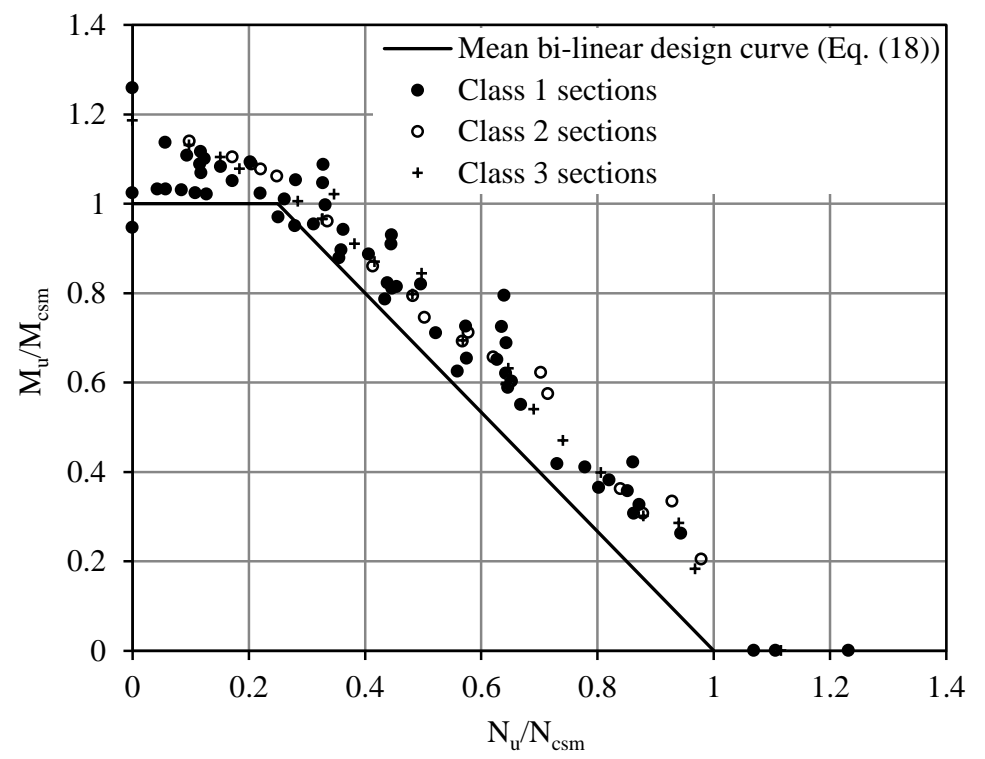

Fig. 15. Normalised austenitic stainless steel combined loading test and FE results by the CSM compression and bending resistances.

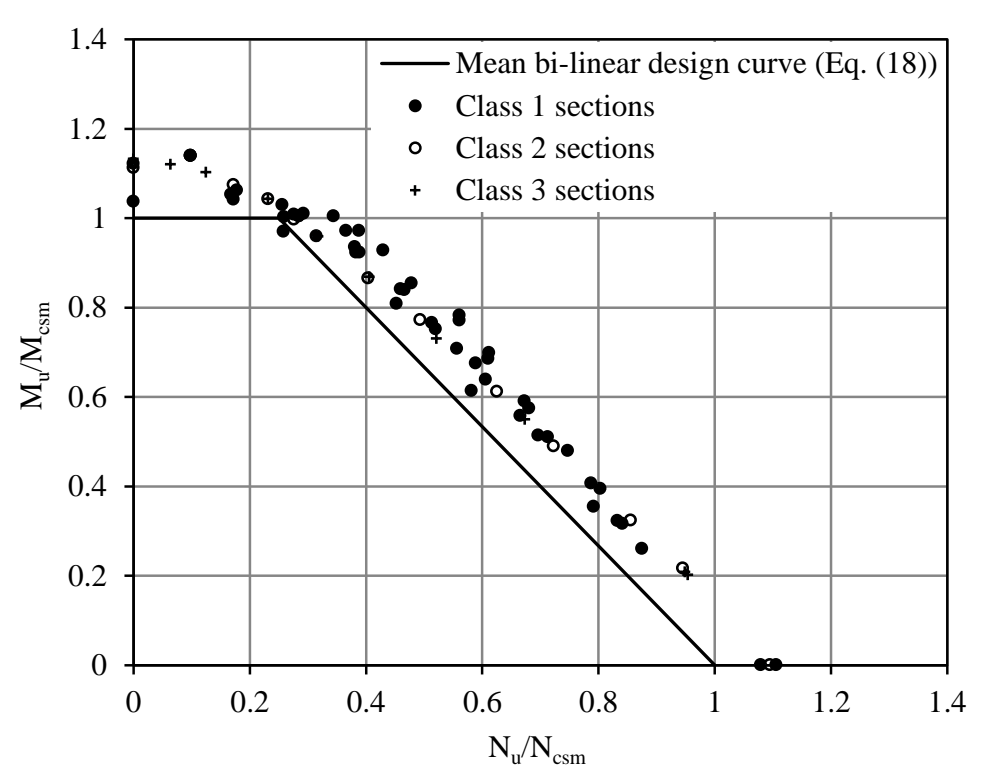

Fig. 16. Normalised lean duplex stainless steel combined loading test and FE results by the CSM compression and bending resistances. 


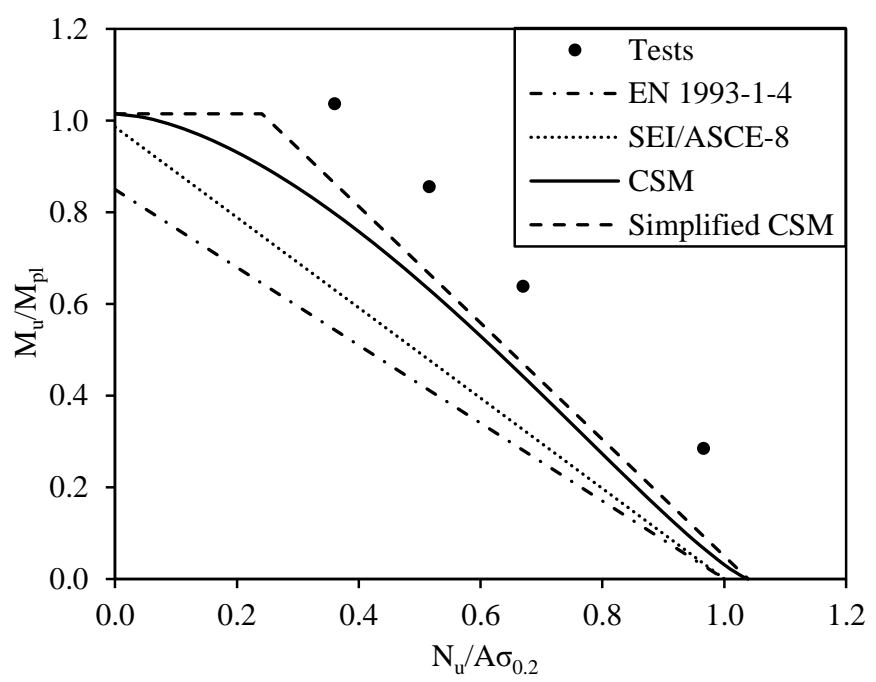

(a) SHS $120 \times 120 \times 5$ specimens.

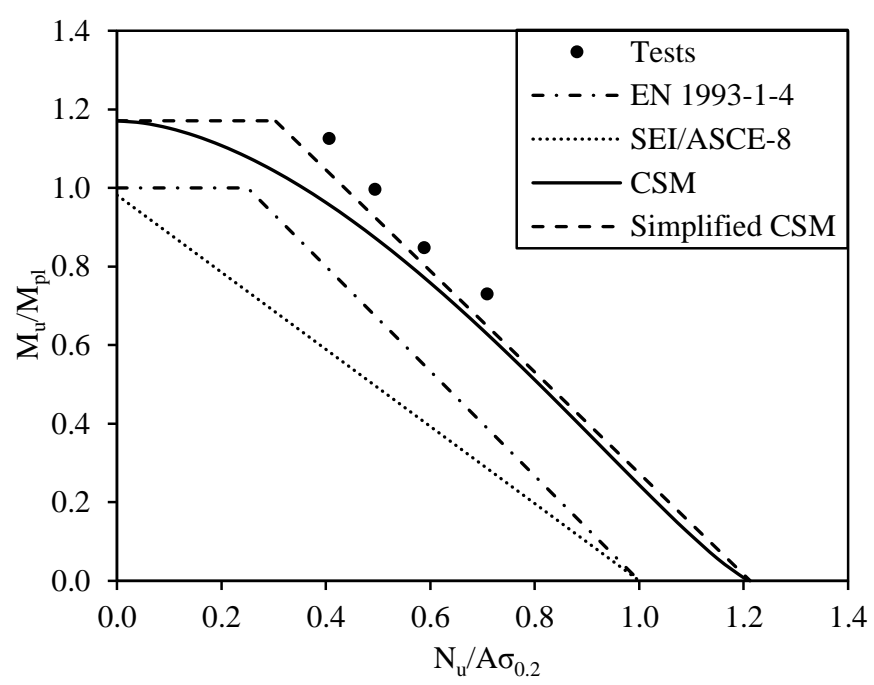

(c) RHS $150 \times 100 \times 6$ specimens.

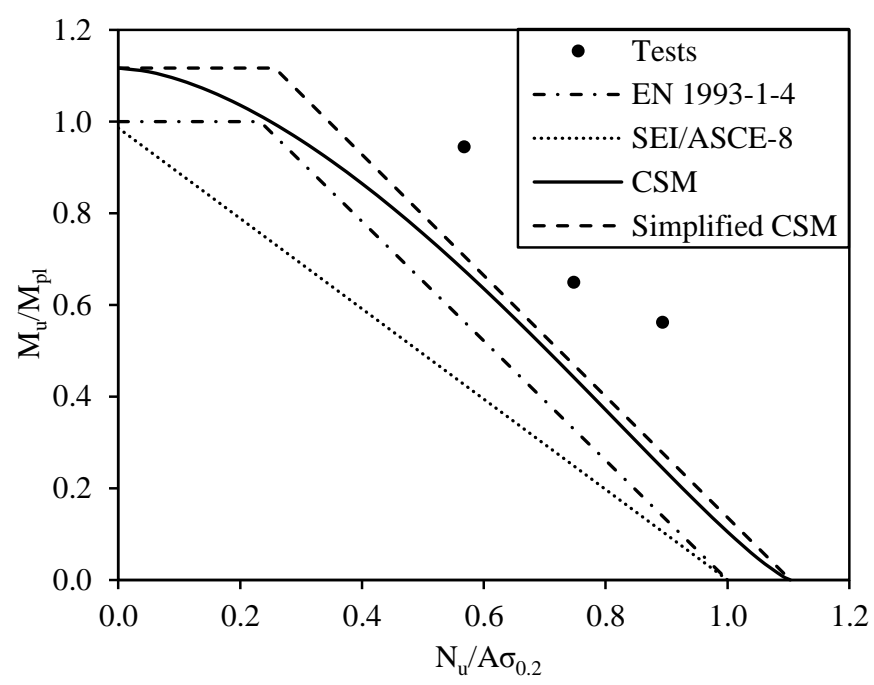

(b) SHS $100 \times 100 \times 5$ specimens.

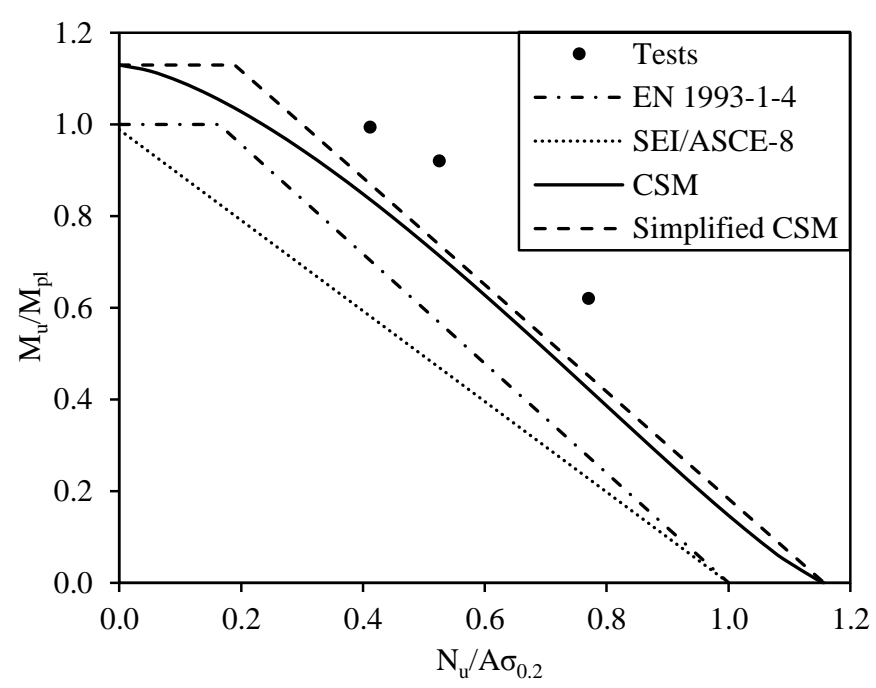

(d) RHS $150 \times 100 \times 8$ specimens.

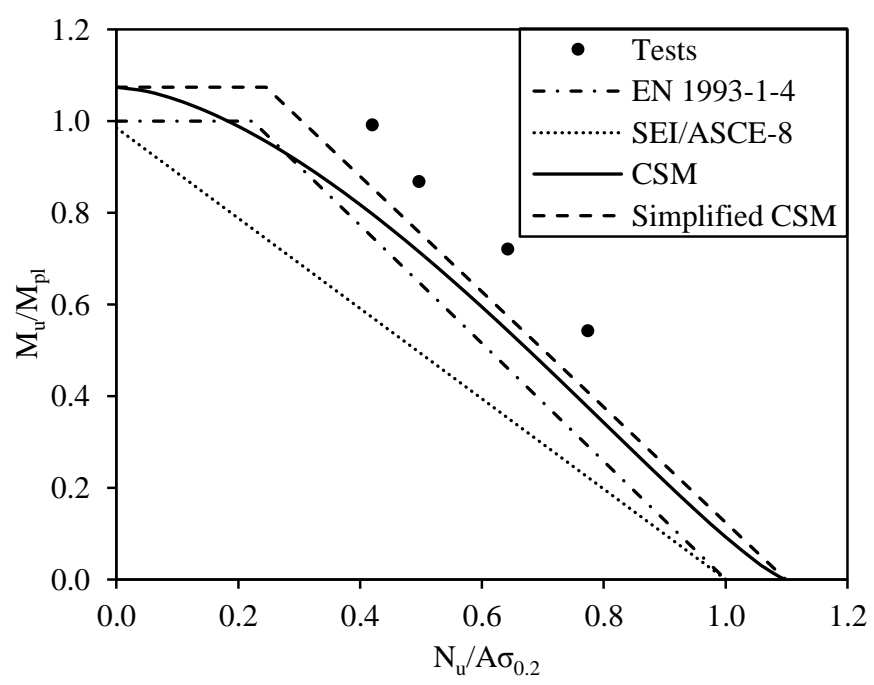

(e) SHS $150 \times 150 \times 8$ specimens.

Fig. 17. Comparison of uniaxial bending plus compression test results with various design interaction curves. 


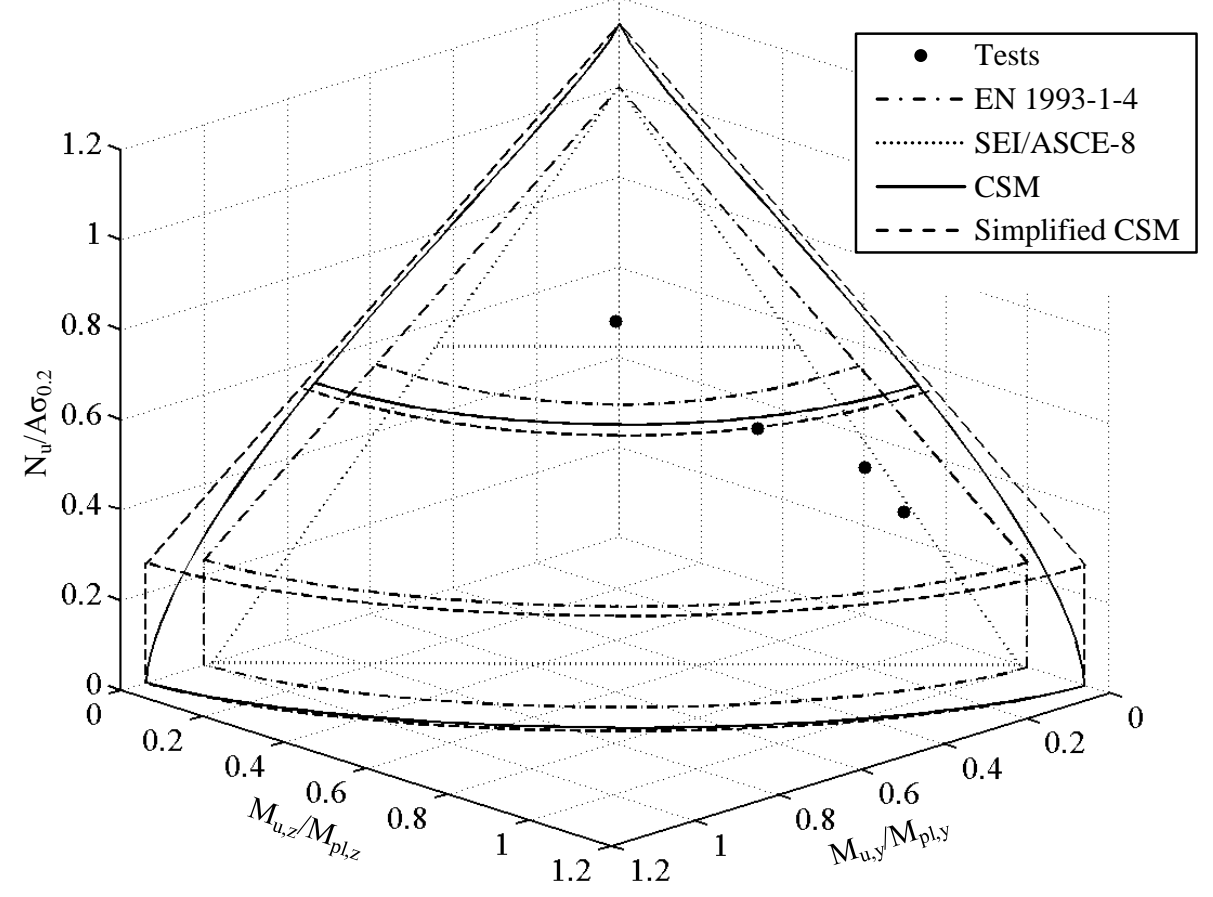

Fig. 18. Comparison of biaxial bending plus compression test results for SHS $100 \times 100 \times 5$ specimens with various design interaction surfaces. 


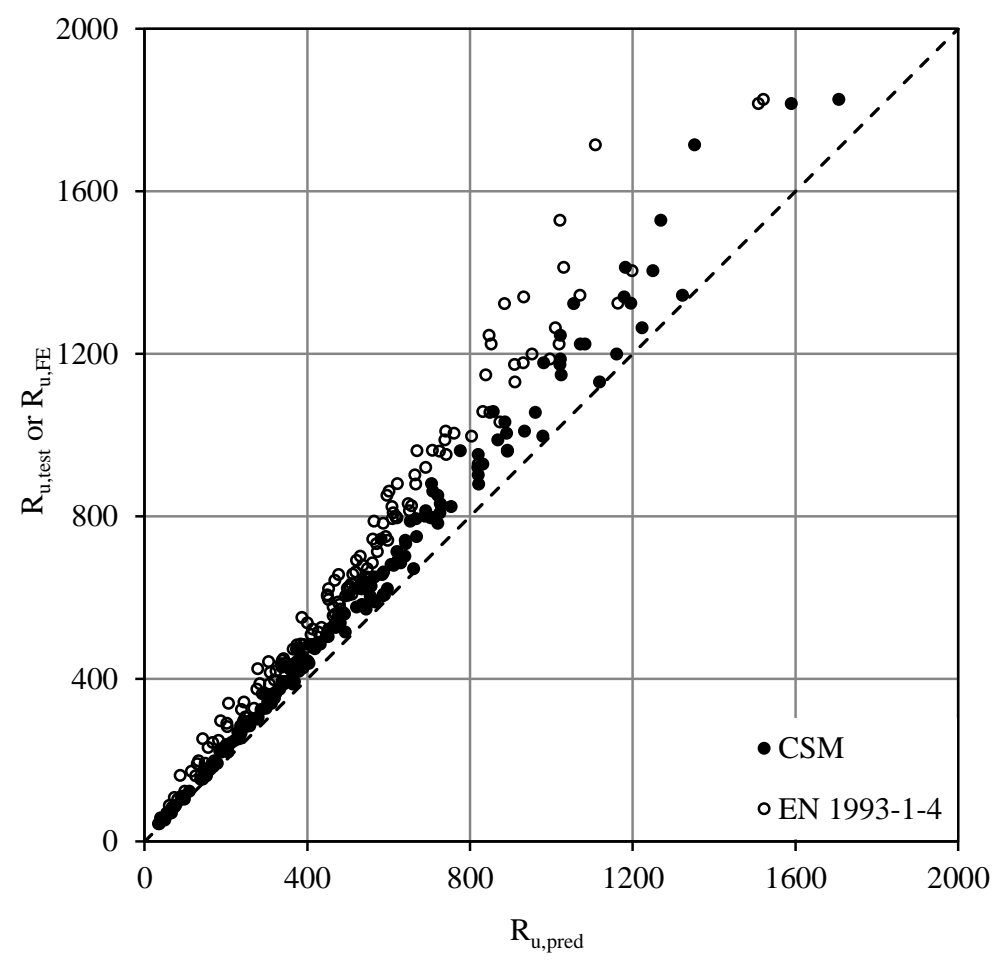

Fig. 19. Comparison of test or FE results with EN 1993-1-4 and CSM predictions for austenitic stainless steel.

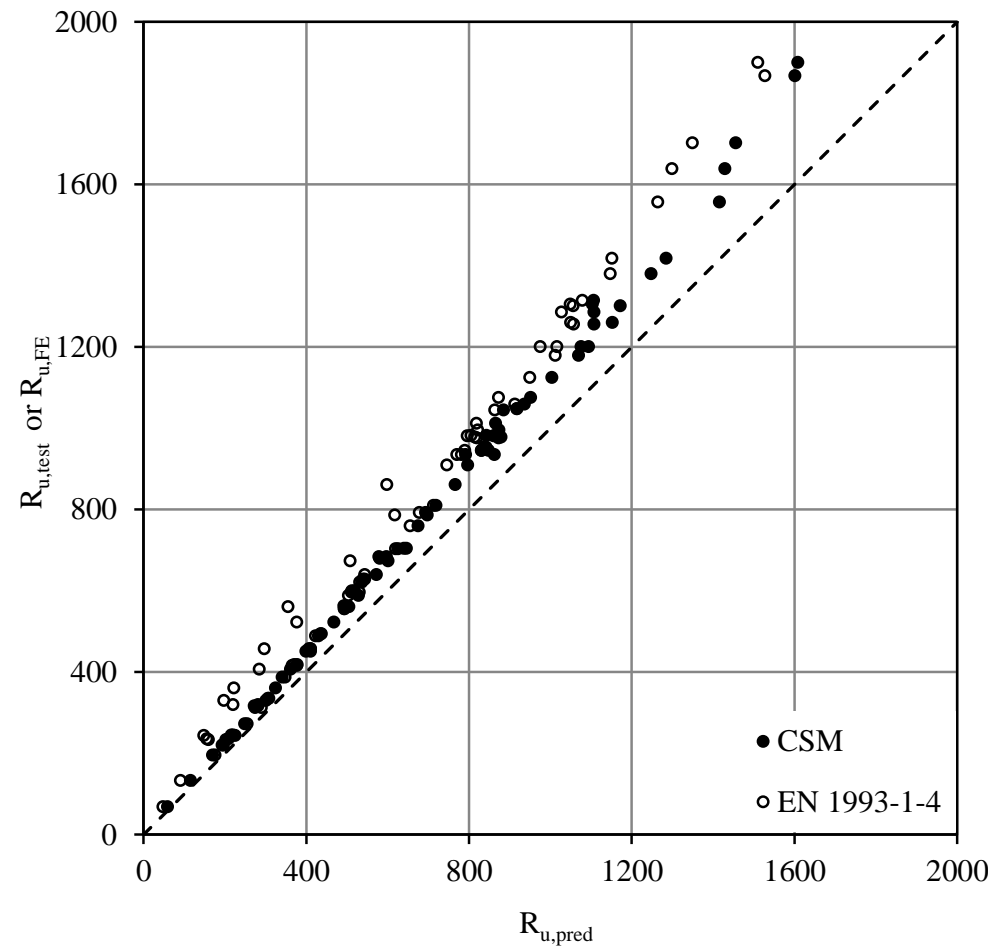

Fig. 20. Comparison of test or FE results with EN 1993-1-4 and CSM predictions for lean duplex stainless steel. 


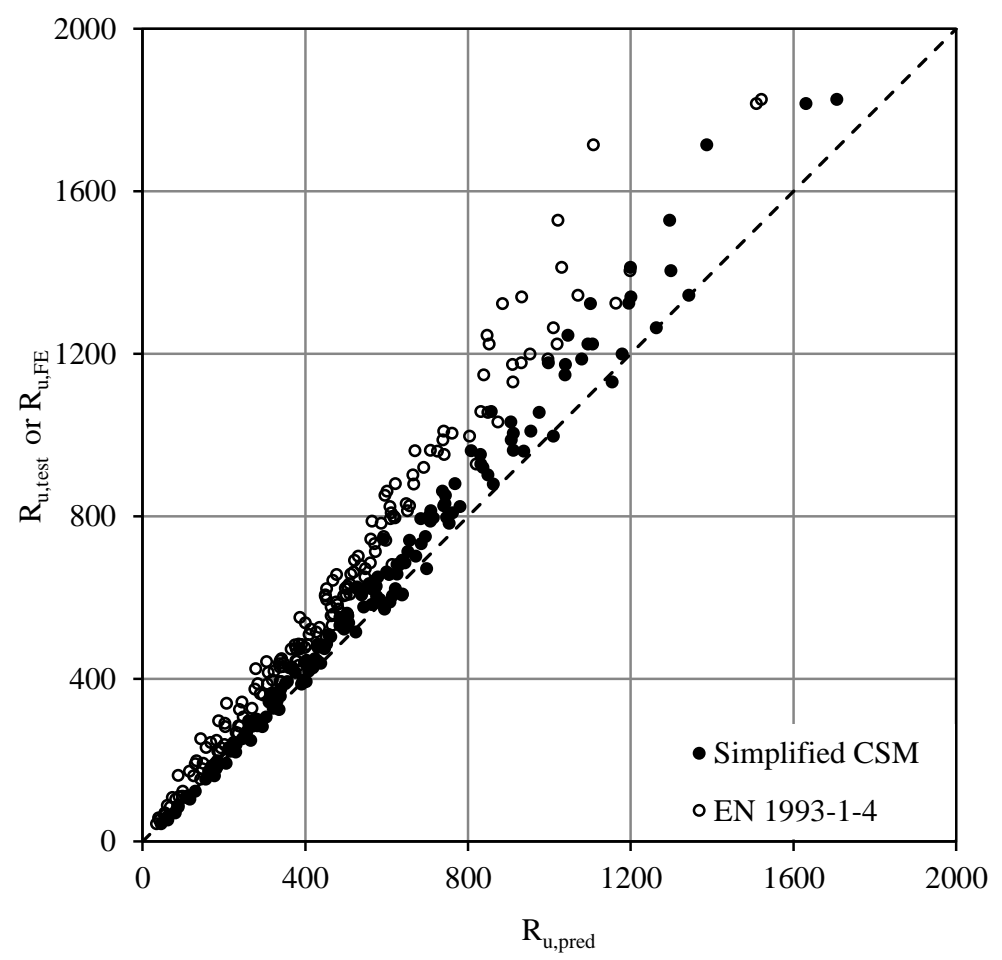

Fig. 21. Comparison of test or FE results with EN 1993-1-4 and Simplified CSM predictions for austenitic stainless steel.

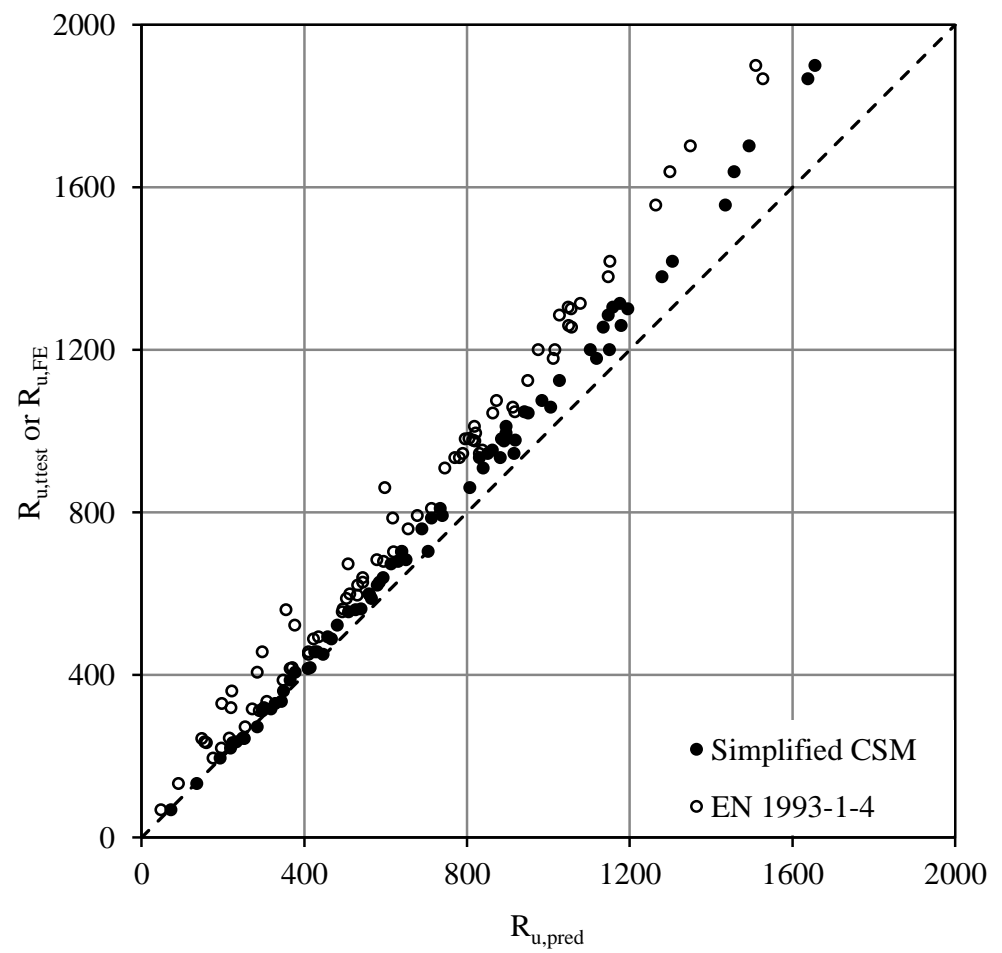

Fig. 22. Comparison of test or FE results with EN 1993-1-4 and Simplified CSM predictions for lean duplex stainless steel. 